\title{
Linking genome wide RNA sequencing with physio-biochemical and cytological responses to catalogue key genes and metabolic pathways for alkalinity stress tolerance in lentil (Lens culinaris Medikus)
}

Dharmendra Singh ${ }^{*}$, Chandan Kumar Singh ${ }^{1}$, Jyoti Taunk², Kishor Gaikwad ${ }^{3}$, Vijayata Singh4, Satish Kumar Sanwal ${ }^{4}$, Sourabh Karwa ${ }^{2}$, Deepti Singh ${ }^{5}$, Parbodh Chander Sharma ${ }^{4}$, Rajendra Kumar Yadav ${ }^{6}$ and Madan $\mathrm{Pal}^{2^{*}}$

\begin{abstract}
Background: Alkaline soils cause low productivity in crop plants including lentil. Alkalinity adaptation strategies in lentil were revealed when morpho-anatomical and physio-biochemical observations were correlated with transcriptomics analysis in tolerant (PDL-1) and sensitive (L-4076) cultivars at seedling stage.

Results: PDL-1 had lesser salt injury and performed better as compared to L-4076. Latter showed severe wilting symptoms and higher accumulation of $\mathrm{Na}^{+}$and lower $\mathrm{K}^{+}$in roots and shoots. PDL-1 performed better under high alkalinity stress which can be attributed to its higher mitotic index, more accumulation of $\mathrm{K}^{+}$in roots and shoots and less aberrantly dividing cells. Also, antioxidant enzyme activities, osmolytes' accumulation, relative water content, membrane stability index and abscisic acid were higher in this cultivar. Differentially expressed genes (DEGs) related to these parameters were upregulated in tolerant genotypes compared to the sensitive one. Significantly up-regulated DEGs were found to be involved in abscisic acid (ABA) signalling and secondary metabolites synthesis. ABA responsive genes viz. dehydrin 1, 9-cis-epoxycarotenoid dioxygenase, ABA-responsive protein 18 and BEL1-like homeodomain protein 1 had $\log _{2}$ fold change above 4.0. A total of 12,836 simple sequence repeats and 4,438 single nucleotide polymorphisms were identified which can be utilized in molecular studies.
\end{abstract}

Conclusions: Phyto-hormones biosynthesis_-predominantly through ABA signalling, and secondary metabolism are the most potent pathways for alkalinity stress tolerance in lentil. Cultivar PDL-1 exhibited high tolerance towards alkalinity stress and can be used in breeding programmes for improving lentil production under alkalinity stress conditions.

Keywords: Alkalinity stress, Abscisic acid, Chromosome lesions, Dehydrin, Epigenetics, Lentil, Secondary metabolites

*Correspondence: dharmendrapbg@rediffmail.com; madanpal@yahoo.com ${ }^{1}$ Division of Genetics, ICAR-Indian Agricultural Research Institute, New Delhi 110012, India

${ }^{2}$ Division of Plant Physiology, Indian Agricultural Research Institute, New Delhi 110012, India

Full list of author information is available at the end of the article

\section{Background}

Alkaline soils affect 434 million hectares of land which cover more than $25 \%$ of the earth's surface (FAO, http:// www.fao.org/soils-portal/soil-management). In these soils, plants face a problem of restricted water supply to 
the roots which is aggravated by the presence of salts like $\mathrm{NaHCO}_{3}$ and $\mathrm{Na}_{2} \mathrm{CO}_{3}$ which are more destructive than neutral salts like $\mathrm{NaCl}$ (causing salinity) [1]. Also, these soils are highly saturated with $\mathrm{CaCO}_{3}$ which limits phosphorous solubility by forming Ca-P compounds, restricting crop productivity in plants [2]. Alkalinity stress triggers acute osmotic stress, ion injury along with high $\mathrm{pH}(>8.5)$ induced injuries [3]. Since third type of injury is not much prevalent in salinity stress, this contributes to higher alkalinity toxicity in plants as compared to the former. High concentrations of $\mathrm{HCO}_{3}$ and $\mathrm{NaHCO}_{3}$ in alkaline soils effects a wide array of metabolic activities in plants leading to stunted growth, leaf chlorosis and distorted anatomical structures [4]. These massive cyto-morphological disorders occur due to increased $\mathrm{Na}^{+}$uptake, nutritional deficiencies, organic acids imbalance, inorganic ions accumulation, disrupted cellular $\mathrm{pH}$, together with decreased enzyme activities and photosynthetic carbon metabolism $[5,6]$. In a comparative study on effect of alkalinity v/s salinity on legume crop Lathyrus quinquenervius, it was found that alkalinity stress was much more devastating. It led to higher inhibition of germination, growth, photosynthesis and root system activities. Alkalinity stress also caused organic acid imbalance, increased $\mathrm{H}_{2} \mathrm{O}_{2}$ and malondialdehyde (MDA) contents, ultimately leading to morphological impairment in this leguminous forage [7].

In order to mitigate alkalinity stress, it is necessary to dissect key genes and metabolic pathways for development of stress tolerant germplasm which can be utilized for breeding purposes. Previous studies indicated that complex molecular mechanisms are associated with tolerance towards $\mathrm{NaHCO}_{3}$ or $\mathrm{Na}_{2} \mathrm{CO}_{3}$ toxicities in crop plants [8]. Manipulation of molecular components including iron transporters, iron reductases and other enzymes have resulted in production of transgenic plants with improved tolerance against low-Fe availability with higher grain yield in calcareous soils $[9,10]$. Some alkalinity tolerant and/or sensitive mutants, such as $p k s 5$ and $j 3$ in Arabidopsis [11]; and alt1 in rice [12] have been isolated and characterized. The mutant chaperone J3 positively regulated alkalinity tolerance by interacting with protein kinase, PKS5 to increase plasma membrane $\mathrm{H}^{+}$-ATPase activity in Arabidopsis [11]. In rice, mutant ALT1, a putative Snf2 family chromatin remodelling ATPase showed enhanced alkalinity tolerance through substantial defence against oxidative stress [12].

Lentil (Lens culinaris Medikus) is a leguminous plant, cultivated throughout Europe, Asia and North America for its highly proteinaceous seeds which serve as staple food for humans and its straw as animal fodder. Furthermore, its ability of nitrogen fixation and carbon sequestration improves soils' nutrient status and thus helps in agricultural sustainability [13]. Globally, it is cultivated on 4.8 Mha with a production of 5.7 MT (FAO STAT, 2019). Lentil is moderately sensitive to both alkalinity and salinity stresses. However, two cultivars namely, PDL-1 and PSL-9 were found to be tolerant against both the stresses $[4,14]$. These cultivars have already been released in India to be cultivated under salt affected soils. Reduced $\mathrm{Na}^{+}$content and increased $\mathrm{K}^{+}$content was found to be associated with tolerance of these cultivars under salinity and alkalinity stress conditions [4, 14].

At the cellular level, tolerant plants can compartmentalize $\mathrm{Na}^{+}$in vacuoles resulting in increase in their tolerance towards high concentration of ions. Evidently, PDL-1 showed lower concentration of $\mathrm{Na}^{+}$and higher concentration of $\mathrm{K}^{+}$in both roots and shoots under long term exposure $(15 \mathrm{~d})$ of alkalinity stress $(40 \mathrm{mM}$ $\mathrm{NaHCO}_{3}$, ) as compared to the sensitive cultivar, L-4076 [4]. PDL-1 has also been registered as a drought tolerant cultivar at National Bureau of Plant Genetic Resources, New Delhi, India in 2017. This cultivar has also showed tolerance against heat stress [15]. Thereby, the cultivar poses to be the most promising lentil cultivar for identifying genes associated with various abiotic stress tolerances including alkalinity.

In last one decade, some attempts have been made to identify genes responsible for alkalinity stress tolerance in crops like sorghum, soybean, jujube, rice, wheat, sugar beet, etc. [16-21]. Most of these studies utilized Ribonucleic acid (RNA)-sequencing (RNA-seq) approach to identify alkalinity responsive genes. RNA-seq is a highly powerful tool for accurate characterization of geneexpression, even at a single nucleotide level under varied stress conditions. However, investigation of stress responsive genes using RNA-seq is limited in lentil. Few studies have utilized this approach to identify drought [22], heat [23] and aluminium (unpublished data) stress responsive genes in lentil. However, exhaustive evaluation of alkalinity responsive genes and its gene regulatory pathways is entirely missing in case of lentil. Therefore, the present investigation was undertaken to i) dissect morpho-anatomical and physio-biochemical changes under alkalinity stress; ii) deduce differentially expressed genes (DEGs) associated with different metabolic pathways involved in response to alkalinity stress; iii) discover simple sequence repeats (SSRs) and single nucleotide polymorphisms (SNPs) among the contrasting cultivars. This investigation will provide deeper insight for genetic improvement of alkalinity stress tolerance in lentil.

\section{Results}

Morpho-anatomical responses under alkalinity stress

Two contrasting lentil cultivars viz. PDL-1 (tolerant) and L-4076 (sensitive) exhibited different response against 

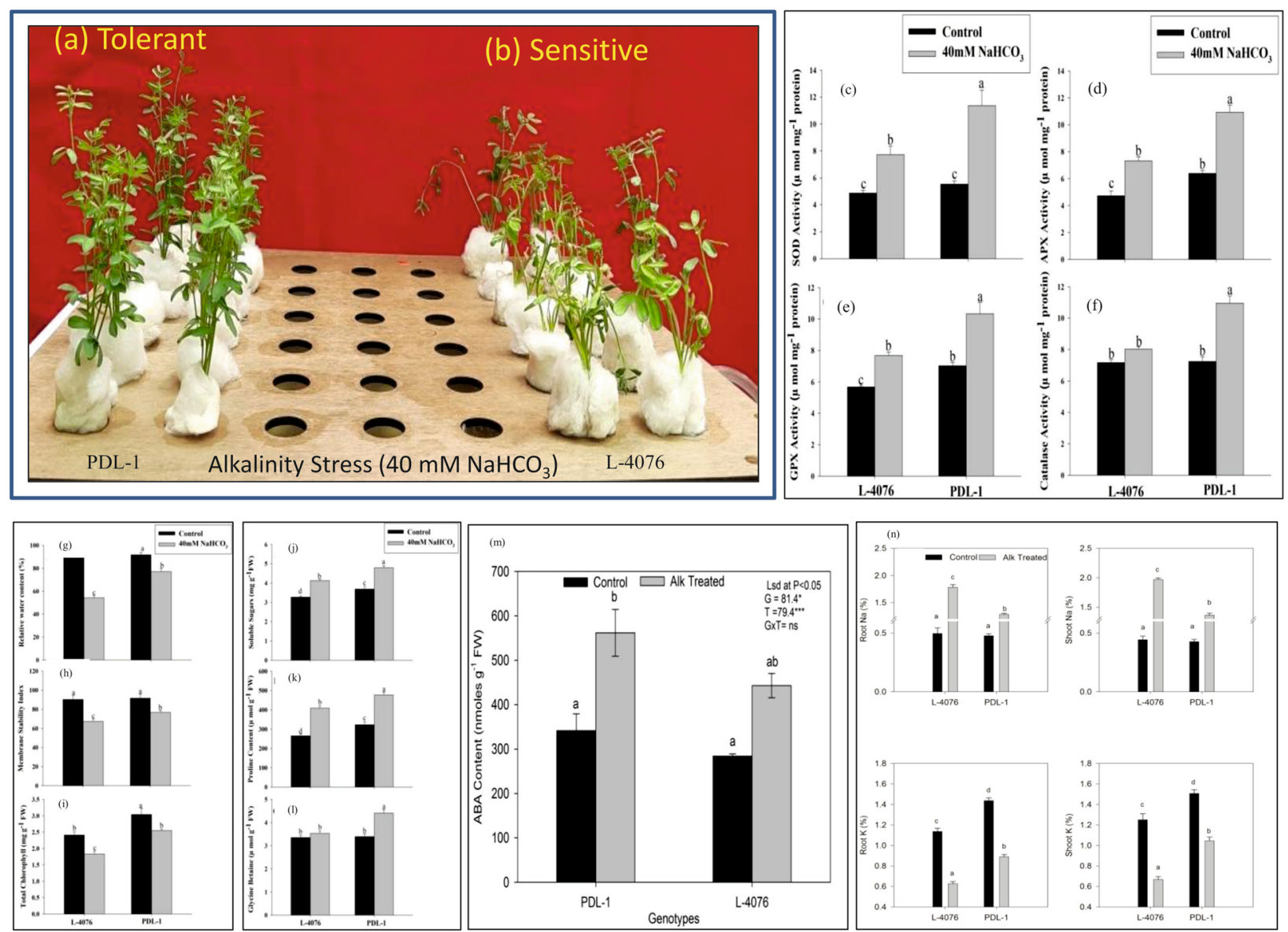

Fig. 1 Morphological response of alkalinity a) tolerant (PDL-1) and b) sensitive (L-4602) cultivars of lentil under $40 \mathrm{mM} \mathrm{NaHCO}_{3}$ stress in hydroponics. Bar graph represents antioxidant enzyme activities of c) Superoxide Dismutase (SOD) d) Ascorbate Peroxidase (APX) e) Glutathione Peroxidase (GPX) f) Catalase; physiological responses in terms of g) Relative Water Content (RWC) h) Membrane Stability Index (MSI), i) Total Chlorophyll content; osmolyte accumulation of $\mathbf{j}$ ) soluble sugar, $\mathbf{k}$ ) proline, I) Glycine betaine; phyto-hormone activity of $\mathbf{m}$ ) Absicisic acid (ABA) along with $\mathbf{n}$ ) root-shoot sodium and potassium contents for both the cultivars under control and alkalinity stress conditions

alkalinity stress. Alkalinity stress symptoms increased in leaves with increase in time duration $(3,5$ and $7 \mathrm{~d})$ in $40 \mathrm{mM} \mathrm{NaHCO}$. Seedlings of sensitive cultivar exhibited severe wilting whereas tolerant cultivar did not show such symptoms even on the fifth day of the alkalinity stress (Fig. 1a, b). This clearly indicates that the most prominent visible differences between tolerant and sensitive cultivars were evident on the fifth day of alkalinity exposure (Fig. $1 \mathrm{a}, \mathrm{b}$ ). Therefore, 5 days time length was considered enough to check initial differences against alkalinity stress and thus the same time period was selected for further physio-biochemical, anatomical and transcriptomic analyses in this study. Data obtained from these analyses revealed that PDL-1 has high tolerance against alkalinity stress and the results are in line with our previous observations [4].
Under control condition, tolerant and sensitive cultivars displayed a well-organized structure of their roots and shoots characterized by intact epidermal cells, multiple layers of cortex tissue and parenchymatous cells (Fig. 2 a-d). Root and shoot anatomy under $40 \mathrm{mM}$ $\mathrm{NaHCO}_{3}$ treated condition showed that the tolerant cultivar maintained good organization of inner root and shoot structures, whereas sensitive cultivar showed disintegration of internal structure along with distortion of root and shoot architectures (Fig. 2 a-d). Thus, the cellular integrity in the tolerant cultivar was much higher as compared to the sensitive one (Fig. 2 a-d). Further, Fluorescein diacetate (FDA) fluorescence signal was increased in roots of both sensitive and tolerant cultivars under stress condition when compared to their respective controls (Fig. $2 \mathrm{e}-\mathrm{h}$ ). However, the intensity of fluorescence 


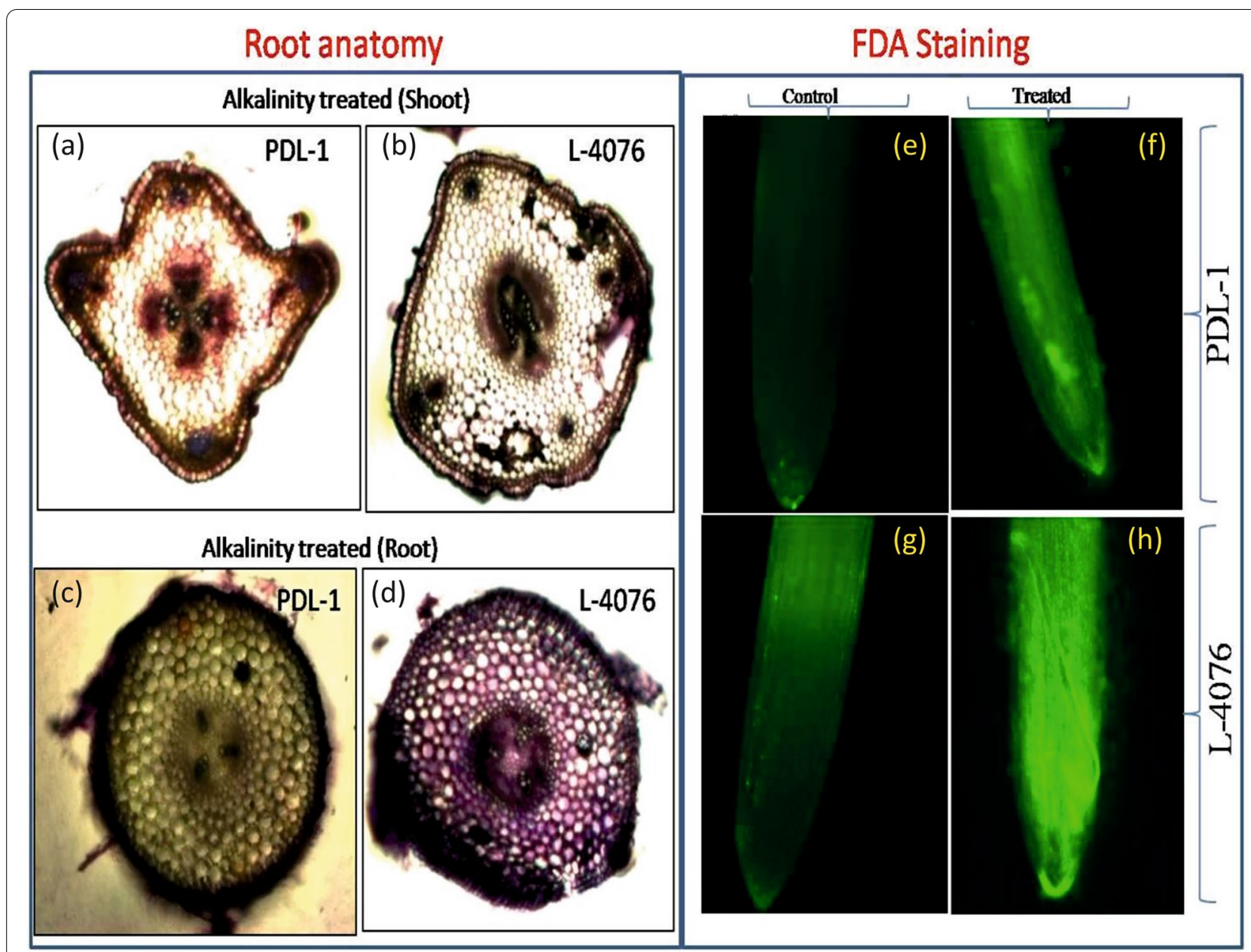

Fig. 2 Free hand cross sections of lentil $\mathbf{a}$, b) shoot $\mathbf{c}$, d) root stained with toulidine blue and $\mathbf{e}-\mathbf{h}$ ) $\mathrm{H}_{2} \mathrm{O}_{2}$ detection in roots using Fluorescein diacetate (FDA) for tolerant (PDL-1) and sensitive (L-4076) cultivars under control and alkalinity stress conditions

signal was much lower in PDL-1 than L-4076 under alkalinity stress (Fig. $2 \mathrm{f}, \mathrm{h}$ ).

\section{Physio-biochemical responses under alkalinity stress}

Variability in physiological parameters; antioxidant enzyme activities viz. superoxide dismutase (SOD), ascorbate peroxidase (APX), glutathione peroxidase (GPX) and catalase (Fig. $1 \mathrm{c}-\mathrm{f}$ ) and accumulation of compatible solutes increased in both the cultivars under alkalinity stress (Fig. 1 g-l). However, antioxidant enzyme activities and accumulation of proline, glycine betaine, soluble sugars, relative water content (RWC), and membrane stability index (MSI) were higher in the tolerant cultivar (PDL-1) as compared to the sensitive one (L-4076) (Fig. 1 g-1). Significant increase in abscisic acid (ABA) content was noticed in both the cultivars under alkalinity stress condition when compared with their controls. However, the content was slightly higher in tolerant cultivar (PDL-1) (Fig. $1 \mathrm{~m}$ ).
$\mathrm{Na}^{+}$and $\mathrm{K}^{+}$contents in roots and shoots of lentil plants were also measured to find out their physiological response. $\mathrm{Na}^{+}$content in roots and shoots of tolerant (PDL-1) and sensitive (L-4076) cultivars was significantly increased under alkalinity stress (Fig. $1 \mathrm{n}$ ). After the $5^{\text {th }}$ day of stress, L-4076 had higher $\mathrm{Na}^{+}$content in both roots and shoots than PDL-1. In contrast, $\mathrm{K}^{+}$contents were dramatically reduced after stress treatment; while PDL-1 had higher $\mathrm{K}^{+}$content in roots and shoots as compared to L-4076. This shows that higher alkalinity tolerance of PDL-1 might be associated with its low accumulation of $\mathrm{Na}^{+}$and high accumulation of $\mathrm{K}^{+}$in both roots and shoots (Fig. 1n).

\section{Cytological changes under alkalinity stress}

Mitotic index (MI) was found higher in both the cultivars under control condition as compared to the alkalinity stress condition after $24 \mathrm{~h}$ (Table S1, Fig. 3). Under 

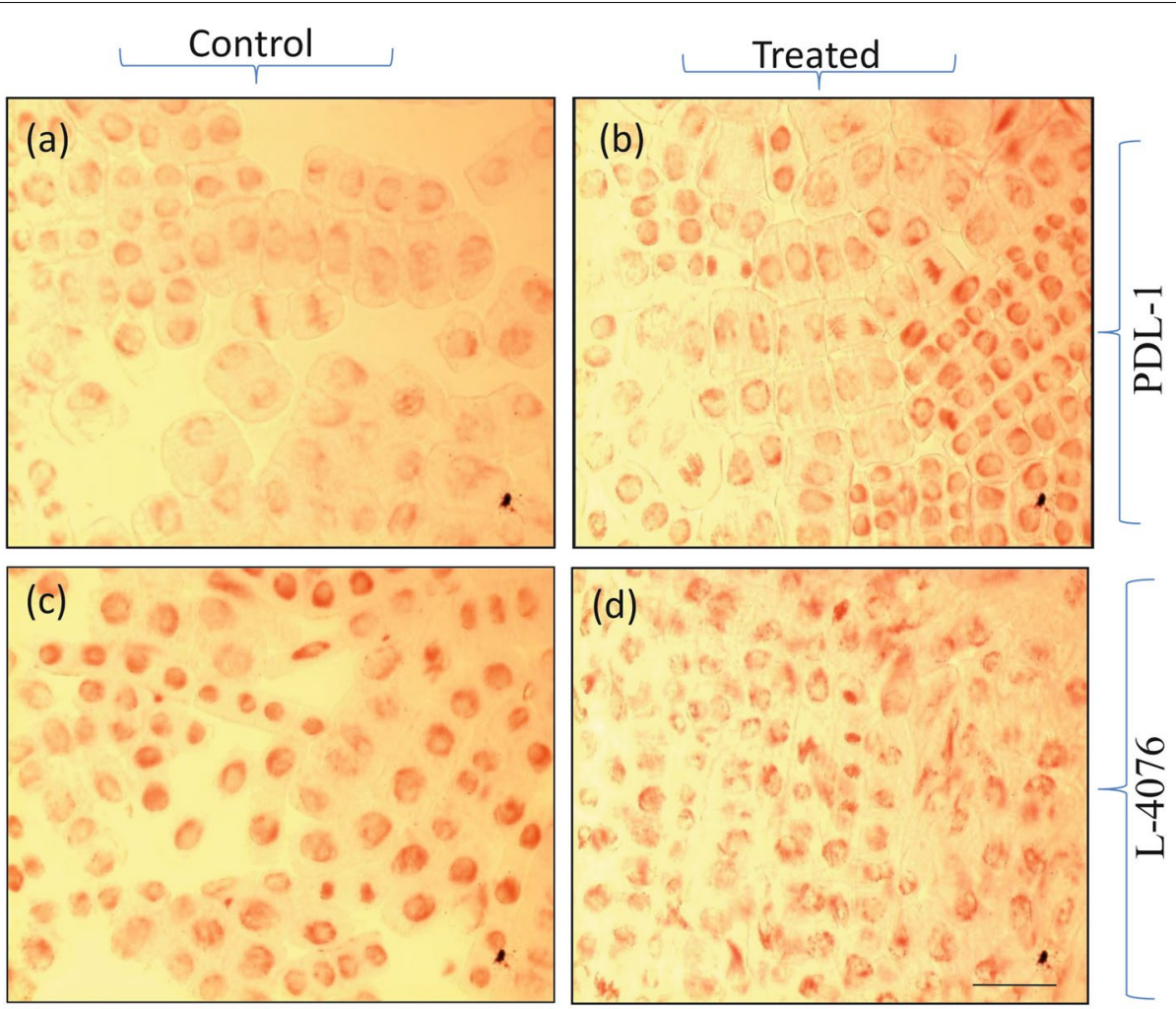

Fig. 3 Microscopic field view of dividing lentil root tip cells of $\mathbf{a}-\mathbf{b}$ ) tolerant and $\mathbf{c}-\mathbf{d}$ ) sensitive cultivars under control and alkalinity stress conditions after $24 \mathrm{~h}$

control condition, MI of sensitive cultivar (L-4076) was much higher than tolerant cultivar (PDL-1). However, with increasing time, chromosomal aberrations and atypically dividing cells were more evident in this cultivar. On the other hand, MI of tolerant cultivar was more under stress condition than that of sensitive cultivar. Moreover, under stress condition, average number of atypically dividing cells was more in case of $\mathrm{L}-4076$ as compared to PDL-1 (Fig. 3 b, d).

\section{De novo assembly and functional annotation of reads}

Average paired-end reads generated through whole transcriptome sequencing for the sample $1 \mathrm{C}, 2 \mathrm{C}, 1 \mathrm{~T}$ and $2 \mathrm{~T}$, including their biological replicates were $57,893,435$, $62,542,645,30,757,579$ and 19,605,802 bp, respectively, where 90.65 to $92.41 \%$ of total reads were mapped. Average number of contigs generated under control and treated samples in contrasting cultivars i.e. PDL-1 and L-4076 were 40,386 (1C), 42,936 (2C), 28,596 (1 T) and $19,730(2 \mathrm{~T}) \mathrm{bp}$ while the longest contig lengths were 19,703 (1C), 15,591 (2C), 15,527 (1 T) and 15,305 (2 T) bp. Average $\mathrm{N}_{50}$ for these samples were 1749 (1C), 1774 (2C), $1176(1 \mathrm{~T})$ and 1055 (2 T) bp (Table S2).

\section{Differential response of genes under alkalinity stress}

Venn diagram showing total number of up and down regulated DEGs under different combinations is represented in Fig. 4. These DEGs were further sorted following the criteria of adjusted $p$-value $\leq 0.05$ and $\log _{2}$ fold change $>1.5$. A total of 1150 genes were assorted which comprises 486 up-regulated and 664 down-regulated DEGs in the combination $1 \mathrm{~T}$ vs $1 \mathrm{C}$. Further, 38 upregulated and 25 down-regulated DEGs were observed in the combination $1 \mathrm{~T}$ vs $2 \mathrm{~T}$. In sensitive cultivar L-4076, a total of 240 up-regulated and 248 down-regulated unigenes were found between control and treated conditions.

\section{Differentially expressed alkalinity responsive genes}

Several alkalinity responsive genes which were differentially expressed under control and treated conditions in contrasting cultivars were identified. Most of these genes were found to be involved in cell cycle regulation, signal transduction, export pathways, together with proteins, carbohydrates and lipids formation. Putative alkalinitystress responsive genes with highest $\log _{2}$ fold changes are listed in Table S3. 


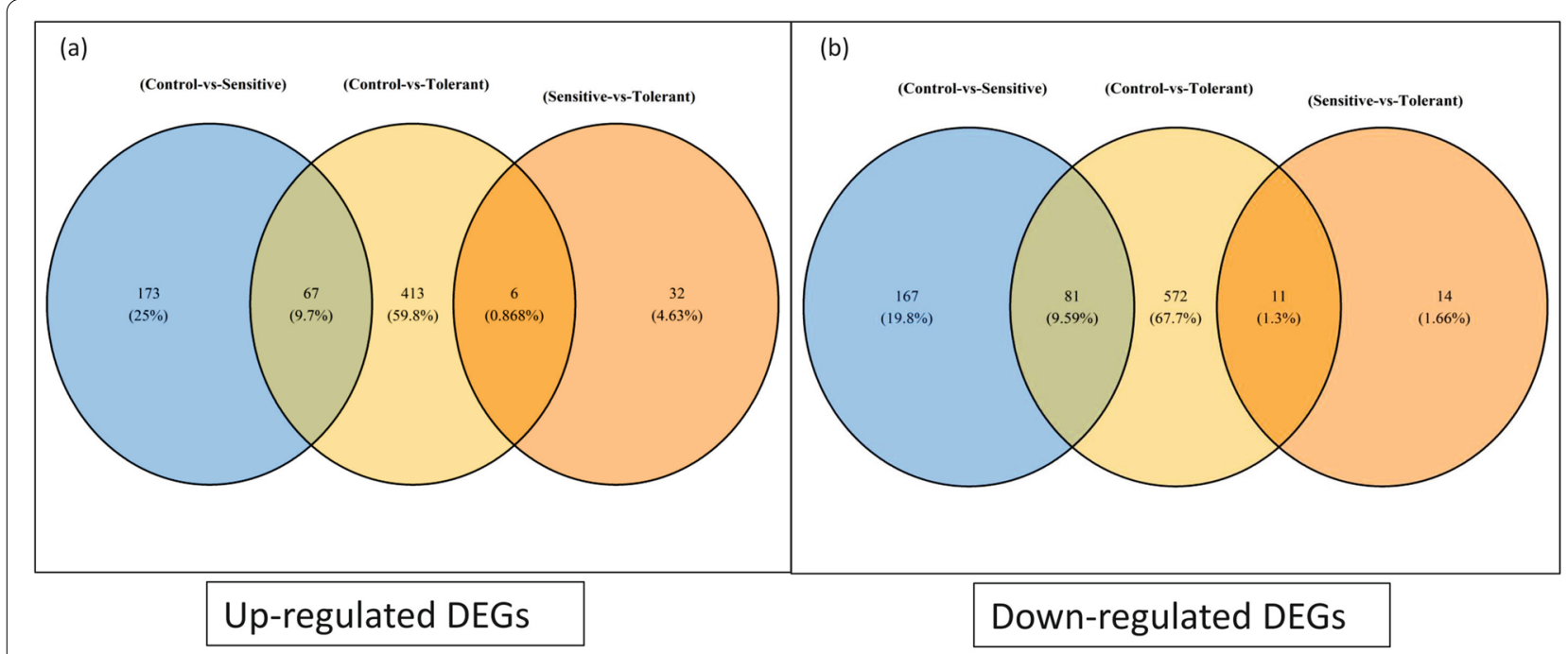

Fig. 4 Venn diagram representing a) up-regulated and b) down-regulated differentially expressed genes (DEGs) in different combinations viz. 1C-1 T, 2C-2 T and 1 T-2 T where 1C: PDL-1 control, 1 T: PDL-1 treated, 2C: L-4076 control and 2T: L-4602 treated

\section{Differentially expressed alkalinity tolerance genes}

In order to identify possible alkalinity tolerance candidate genes in lentil, DEGs between alkalinity treated contrasting cultivars (PDL-1 v/s L-4076) were filtered out. Twenty-two DEGs were found to be associated with root-shoot growth and development. Seven DEGs were involved in root nodule formation, whereas 5 DEGs were related to chlorophyll biosynthesis. Thirty-two DEGs were involved in inter-membrane trafficking and microtubules movement. Seventeen DEGs were found to be associated with antioxidant compounds and secondary metabolism. Twenty seven DEGs were responsible for reconciliation of mitosis and cell division, whereas 21 DEGs adhere to orchestration of epigenetic responses. A total of 12, 118 and 134 DEGs were related to cell wall; ion channels and transporters; and intracellular signalling mediated by calcium, lipids, transcription factors, and phyto-hormones; respectively. Heat maps showing DEGs related to phyto-hormones that were found to be up-regulated in tolerant cultivar $(1 \mathrm{~T})$ under alkalinity stress are represented in Fig. 5. Categorical representation of top up and down regulated DEGs along with their associated functions in alkalinity stress response is summarized in Table S4. Circos plots were also generated for up and down-regulated DEGs between contrasting cultivars under control and treated conditions (Fig. S1).

\section{SNP and SSR calling}

A total of 12,836 SSRs were identified in this investigation, of which $2 \mathrm{C}$ had the maximum number of SSRs i.e., 7860 followed by $1 C$ which had 7299 SSRs. Under alkalinity stress conditions, $1 \mathrm{~T}$ showed more SSRs (3300) compared to $2 \mathrm{~T}$ which had only 2032 SSRs. Total number of SNP variants identified within samples of tolerant and sensitive cultivars under treated conditions were 933 and 1146, respectively.

\section{Pathway analysis}

All the unigenes detected in this study were categorized into Gene Ontology (GO) terms, based on nucleotide sequence similarity (Fig. 6). These GO terms were further broken down into three major categories consisting of biological processes, cellular components and molecular functions. Out of the three major categories, highest number of unigenes belonged to the biological processes (Fig. 6). MapMan based analysis revealed alterations in metabolic pathways that occur during alkalinity stress (Fig S2). Metabolic overview map of sensitive $\mathrm{v} / \mathrm{s}$ tolerant treated cultivars elucidated that antioxidant machinery, glycolysis, large enzyme families, lipid biosynthesis, mitochondrial electron transport, sucrose synthesis, phyto-hormones and secondary metabolism were the major pathways affected by alkalinity stress. Genes involved in phyto-hormones and secondary metabolites biosynthesis pathways i.e. mevalonic acid (MVA) pathway, phenolics, lignins, and flavonoid synthesis pathways, etc. were found to be affected by alkalinity stress in both the cultivars (Fig S2). Results observed through MapMan based analysis were in compliance with the transcriptomic analysis. Transcriptome data reported multiple DEGs related to carbohydrate anabolism and catabolism reflecting altered glycolysis in MapMan analysis. Similarly, multiple DEGs related to redox homeostasis, cell 

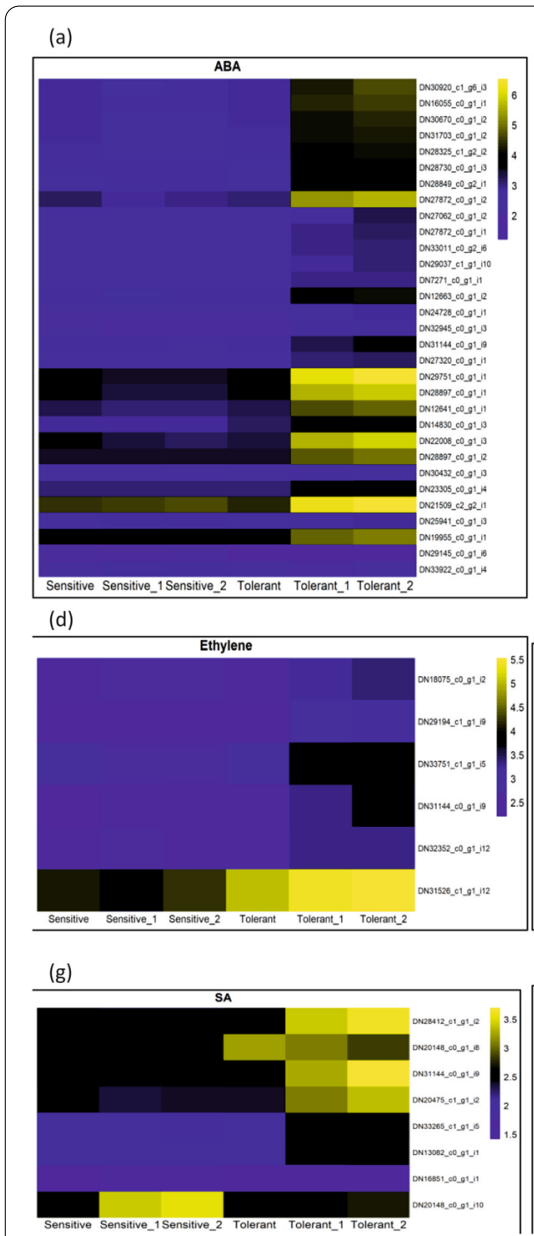

(b)

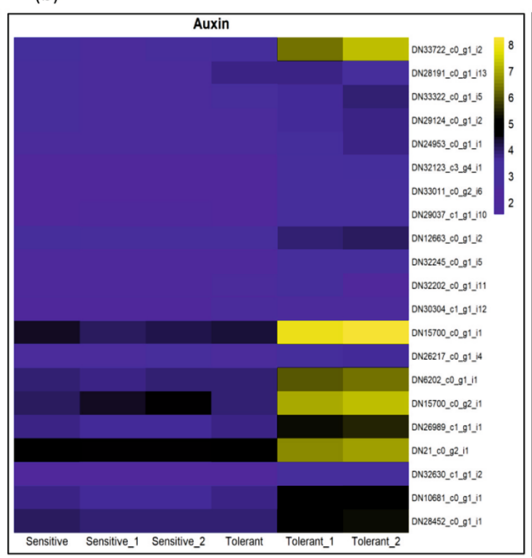

(e)

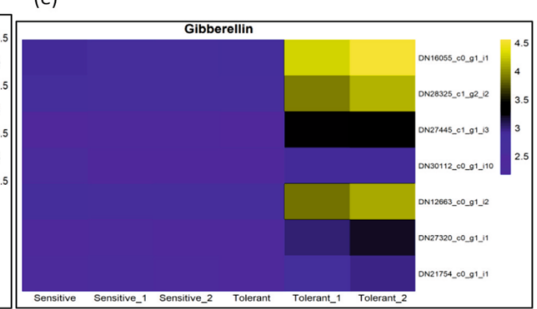

(h)

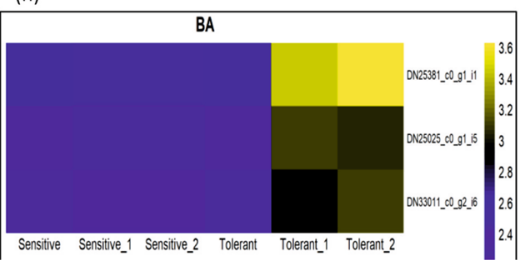

(c)

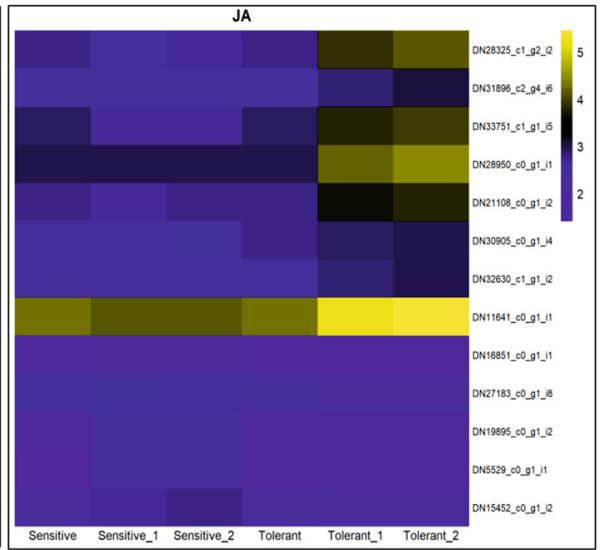

(f)

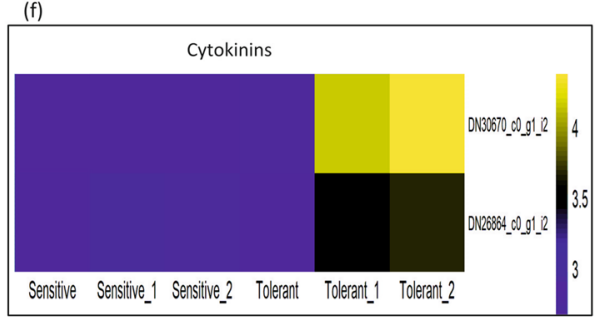

Fig. 5 Heat maps showing differential expression of phyto-hormone related differentially expressed genes (DEGs) under alkalinity stress for a) absicisic acid (ABA), b) auxin, c) jasmonic acid (JA), d) ethylene, e) gibberellin, f) cytokinins, g) salicylic acid and $\mathbf{h}$ ) Brassinosteroids (BR) in alkalinity tolerant and sensitive lentil cultivars. DN33722_c0_g1_i2 in part b) represents Auxin transport protein BIG which has been validated in qRT-PCR. First three columns of heat map represent replicates of sensitive cultivar (L-4076), whereas last three columns represent replicates of tolerant cultivar (PDL-1)

wall modifications, phyto-hormone synthesis, signalling and secondary metabolites production were also represented in MapMan analysis. Schematic representation of putative DEGs and pathways involved in response to alkalinity stress is represented in Fig. 7 (a). Present study also emphasized upon the induction of ABA related DEGs under alkalinity stress. Thereby, detailed schematic representation of all the DEGs related to ABA pathways is presented in Fig. 7 (b).

\section{Quantitative real time polymerase chain reaction (qRT-PCR) validation}

In order to validate the results obtained from transcriptomic analysis, qRT-PCR analysis was undertaken using 10 significant genes (Table S5). The relative expression of these DEGs under different combinations is represented in Fig. 8. The observed fold change in qRT-PCR expression results were in accordance with the transcriptomic data, although differences were noted in the absolute expression levels as represented in Fig. 8. Regression plot showed that expression data of next generation sequencing (NGS) and qRT-PCR were found to be highly correlated (Fig S3).

\section{Discussion}

Alkalinity stress is one of the environmental factors that cause physiological stress in plants limiting plant growth and productivity together with generating negative effects on grain quality parameters [24, 25]. Previously, we reported that alkalinity stress considerably reduced plant growth in 285 lentil genotypes at the seedling stage. Also, the seed yield of these genotypes was reduced by $27-87 \%$ and $83-100 \%$ under alkaline field conditions having soil pH of 9.0 and 9.5, respectively [4]. Based on their 


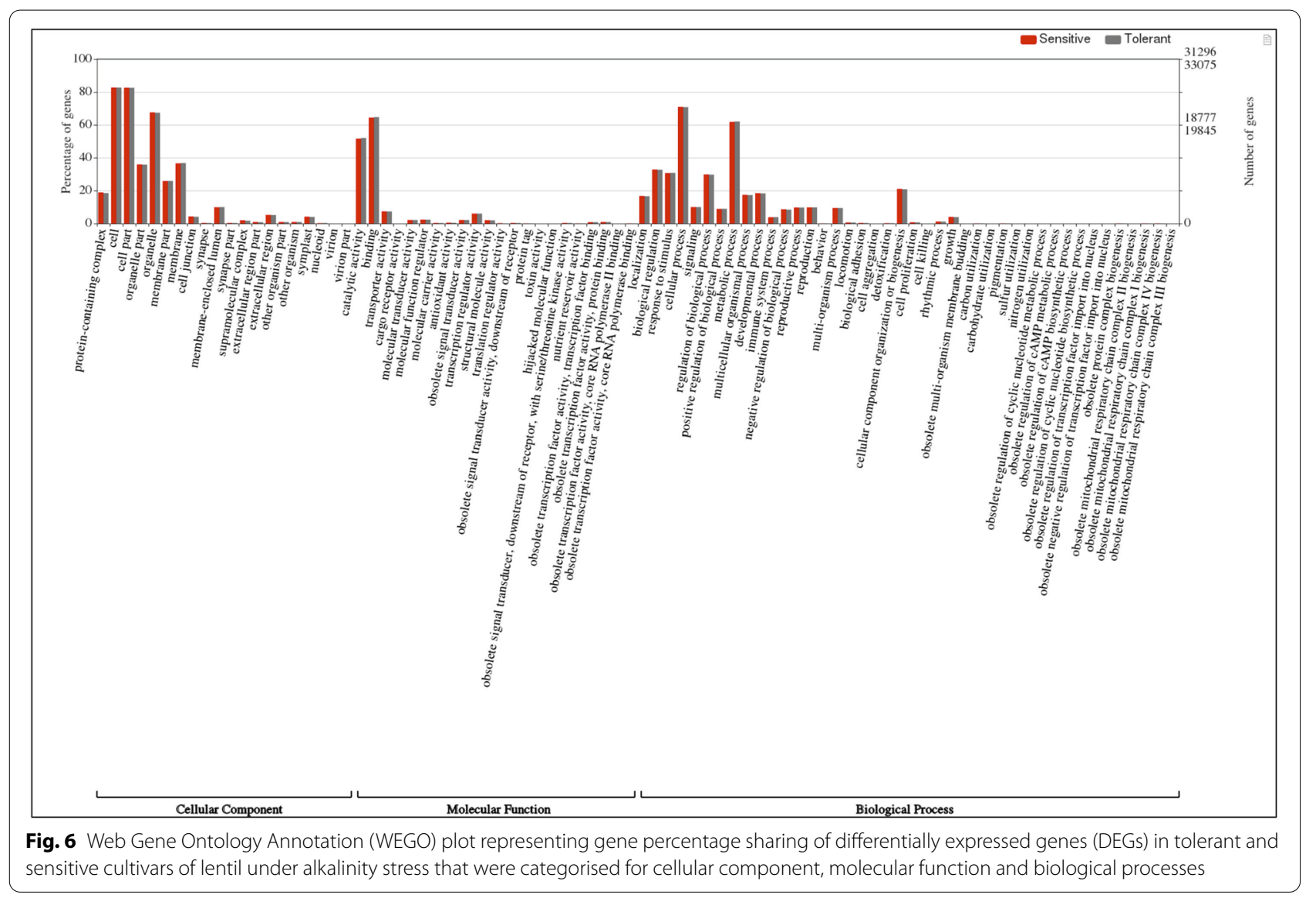

morpho-physiological responses, the study also clustered these genotypes into contrasting groups for alkalinity stress tolerance. Following this analysis, two highly contrasting genotypes i.e. PDL-1 and L-4076 were selected for the present study to decipher putative genes and pathways involved in response to alkalinity stress. The selected cultivars have already been used as contrasting cultivars in molecular mapping of salt [14], heat [15] and drought [26] tolerance gene(s), since in our preliminary molecular diversity studies, they were clustered into contrasting groups when analysed under respective stress conditions $[14,15,22]$.

In the present study, different physio-biochemical, cytological and molecular analyses were conducted during seedling stage, since in most of the leguminous crops, this stage is considered to be very sensitive as compared to other developmental stages under different abiotic stresses and the stage is critical for plant growth and overall survival [27-29].

\section{DEGs associated with morpho-anatomical} and physio-biochemical parameters under alkalinity stress Wilting and necrosis are common symptoms of morphological damage due to excess of salt [30]. By the end of fifth day of the treatment, severe wilting and necrosis were predominant in L-4076 seedlings under alkalinity stress which was not the case with tolerant cultivar, PDL-1. Similar results were also obtained in our previous study under long term alkalinity stress [4]. Plants maintain their alkalinity tolerance mechanism by preventing $\mathrm{K}^{+}$efflux and promoting $\mathrm{Na}^{+}$efflux from the cells to maintain their membrane potential $[31,32]$. Similarly, in the present study, high alkalinity tolerance of PDL-1 can be linked to its capability to accumulate higher $\mathrm{K}^{+}$content in both roots and shoots as compared to L-4076 (Fig. $1 \mathrm{n}$ ).

FDA staining of root tips can detect $\mathrm{H}_{2} \mathrm{O}_{2}$ levels under alkalinity stress, which directly corresponds to the intensity of fluorescent signals. In a study by Biswas and Mano [33], it was found that salt stress together with increased $\mathrm{H}_{2} \mathrm{O}_{2}$ induced programmed cell death increased fluorescent signals in root tips of tobacco and Arabidopsis. In the present study, PDL-1 showed lower intensity signals as compared to L-4076, which is attributed to high tolerance of PDL-1 towards alkalinity (Fig. $2 \mathrm{i}-1$ ).

Antioxidant enzyme activities and accumulation of low molecular weight osmolytes like proline, glycine betaine, together with soluble sugars and RWC were 

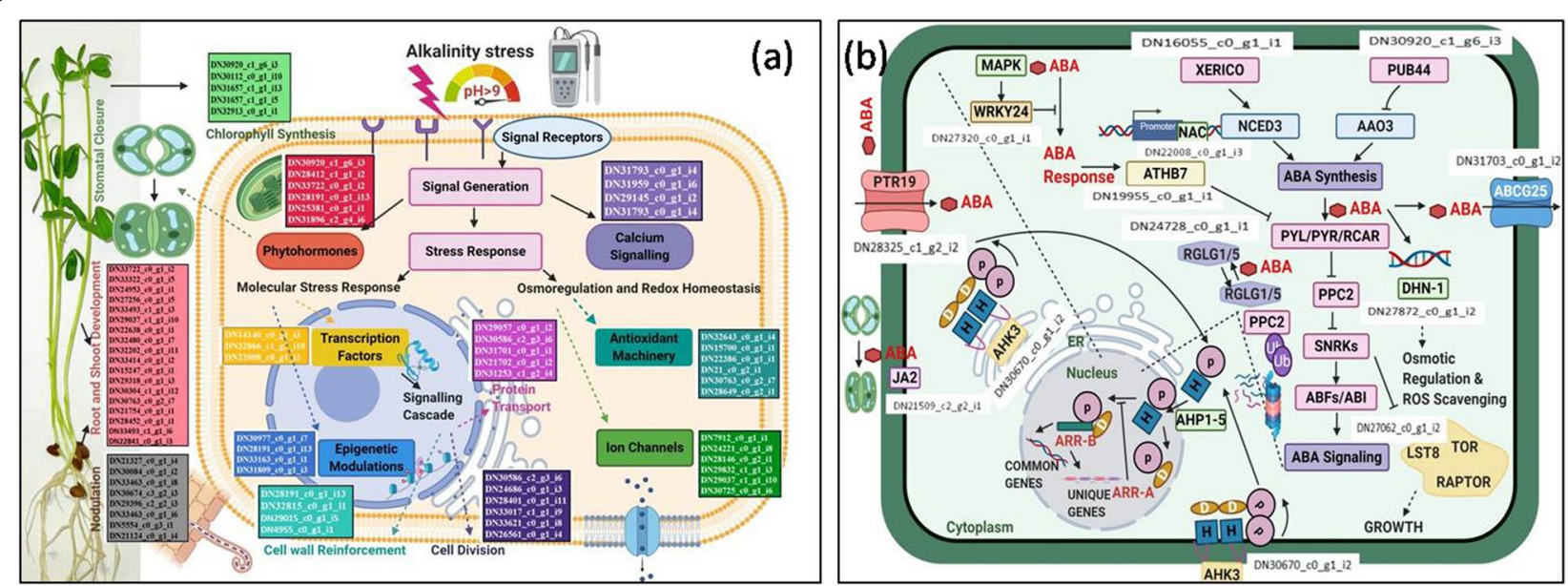

Fig. 7 Schematic representation of (a) overall putative differentially expressed genes (DEGs) and modulated pathways in response to alkalinity stress, b) Detailed description of DEGs related to ABA pathways which were induced due to alkalinity stress. PUB44: Promotes the degradation of AAO3 and thus represses abscisic acid (ABA) biosynthesis; XERICO: Function on ABA homeostasis at post-translational level, probably through ubiquitin/proteasome-dependent substrate-specific degradation; AHK3: Redundant negative regulator of ABA signalling; ABC25G: High affinity ABA transporter that mediates export of $A B A$, with a preference for (+)-ABA, through the plasma membrane, especially in vascular tissues (e.g. phloem companion cells), and is involved in the intercellular ABA signalling pathway; PTR19: Mediates cellular ABA uptake; DHN1: Induced by ABA; LST8: Involved in plant growth; RGLG5: Mediates ubiquitination and subsequent proteasomal degradation of the target protein PP2CA, a major inhibitor of ABA signalling; WRKY24: Negative regulator of ABA signalling via specific repression of ABA-induced promoters; NAC2: Transcription factor that activates the expression of senescence and ABA associated genes including NCED1, ABCG40, CYP707A2, SAG113, SGR1 and PAO, by directly binding to their promoters; JA2: Regulates the expression of NCED1, and required for the stomatal closure. Both the images are created with BioRender.com

found to be higher in the tolerant cultivar (PDL-1) as compared to the sensitive one (L-4076). Antioxidant enzymes and osmolytes provide tolerance against oxidative stress in plants and helps in balancing ions in the cells [14]. Enhanced redox processes in lentil seedlings are evidenced by increased $\mathrm{H}_{2} \mathrm{O}_{2}$ content and subsequent increase in peroxidase activities, due to alkalinity treatment (Fig. 1 c-f and Fig. $2 \mathrm{i}-1$ ). Present findings are in line with the study on biochemical response towards alkalinity stress in rice [34]. Zhang et al. [34] studied effect of alkalinity on root tips and observed marked accumulation of ROS and $\mathrm{H}_{2} \mathrm{O}_{2}$. Further, increased antioxidant enzyme activities such as that of SOD, catalase, peroxidase and APX resulted in reduced ROS accumulation in rice roots.

In the present study, transcriptomic data also corresponded to physio-biochemical results. For example, DEG that encoded peroxidase (DN15700_c0_g1_i1), was found to be significantly up-regulated in the combination $1 \mathrm{~T}-2 \mathrm{~T}$. Peroxidase enzyme is responsible for catalysis of $\mathrm{H}_{2} \mathrm{O}_{2}$, oxidation of toxic reductants, biosynthesis and degradation of lignin, suberization, auxin catabolism and response to oxidative stress [35]. As reported by Zhang et al. [34], alkalinity stress causes root damage by inducing accumulation of $\mathrm{ROS}$ and $\mathrm{H}_{2} \mathrm{O}_{2}$. Thus, upregulation of peroxidase in the present study indicates neutralization of ROS generated during stress. PDL-1 showed higher activities of peroxidase enzymes viz. GPX and APX which resulted in tolerance towards alkalinity stress conditions. DEGs annotated for peroxidase family (DN15700_c0_g1_i1, DN10681_c0_g1_i1) were found to be up-regulated more significantly in PDL-1 compared to L-4076. Similar results were also found in other studies in wild jujube and salsa leaves under alkalinity and salinity stress, respectively $[18,36]$.

\section{DEGs associated with cytological changes under alkalinity stress}

Cells in root tips divide constantly when roots are directly exposed to high salt concentrations. Mitotic activity evaluated as MI is an important parameter for studying such cytotoxic effects. Exposure to high alkalinity stress has led to abnormal chromosomal behaviour in root tip cells of rye and other crops $[37,38]$. A high amount of salt can interfere with the osmotic balance of the cells and thus can generate ROS which affects DNA [39]. Evidently, highly reactive hydroxyl radical $\left({ }^{\circ} \mathrm{OH}\right)$ species adds double bonds to DNA bases and abstracts $\mathrm{H}$ atom from the thymine's methyl group and each of the $\mathrm{C}-\mathrm{H}$ bonds of $2^{\prime}$ deoxyribose [40] and therefore, have genotoxic effects on cells under salt / alkalinity stress conditions. In the present study, chromosomal aberrations and poorly dividing 

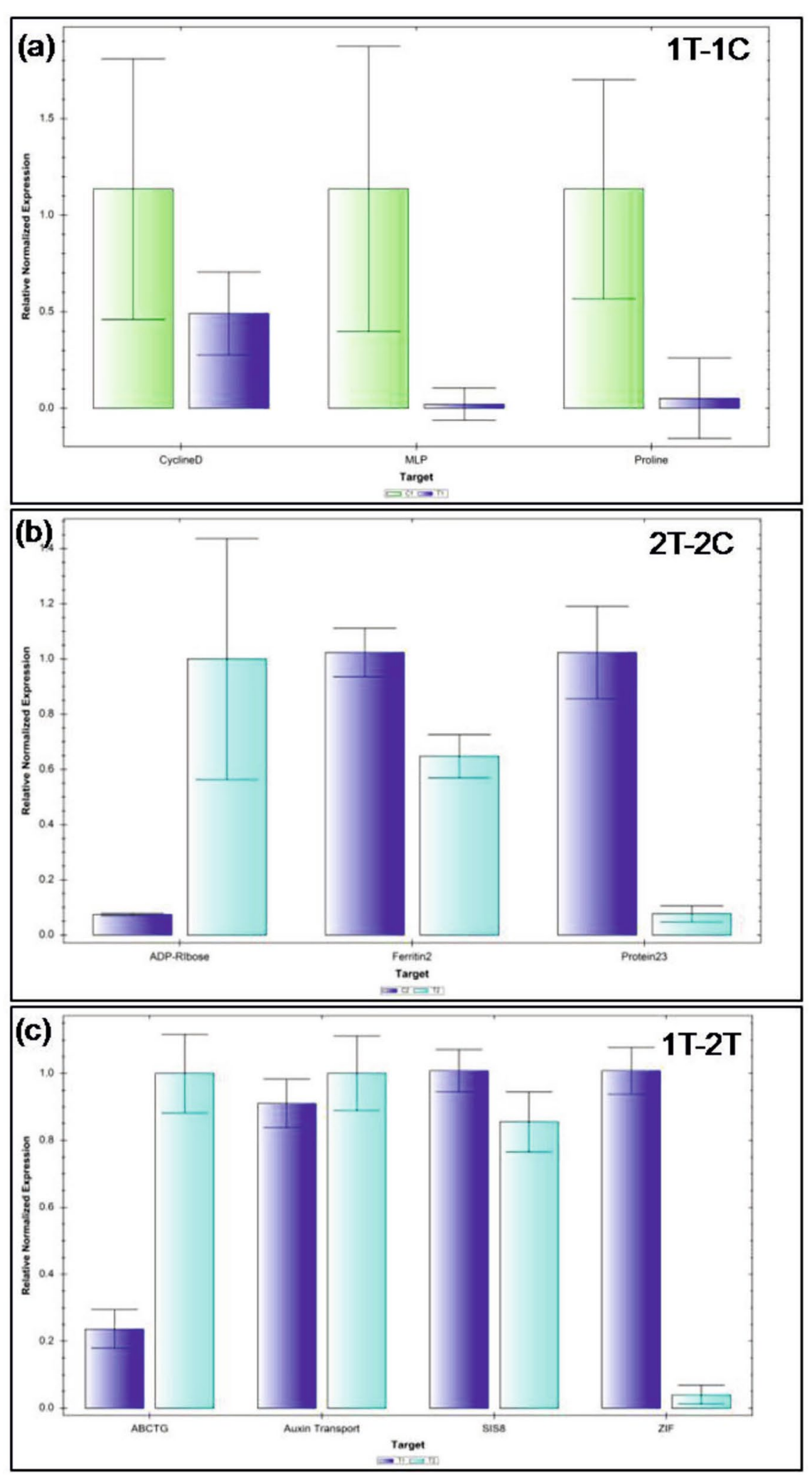

Fig. 8 Bar graph representing relative expression of 10 selected differentially expressed genes (DEGs) using quantitative real-time -polymerase chain reaction (qRT-PCR) in different combinations i.e. 1C-1T, 2C-2T, 1T-2T to validate next-generation sequencing (NGS) results of lentil cultivars under alkalinity stress conditions, where 1C: PDL-1 control, 1T: PDL-1 treated, 2C: L-4076 control and 2T: L-4602 treated 
cells were quite visible after $24 \mathrm{~h}$ and $48 \mathrm{~h}$ of alkalinity treatment in both the cultivars. The possible explanation for the above-mentioned observation could be increase in ROS-related cytotoxicity, since high salt/alkali stress generates ROS which impacts the chromosome arrangement or can create lesions in chromosome, disrupts spindle formation, etc. [39].

Differential gene expression analysis of both the cultivars suggested involvement of genes coding for protein MEI2-like 2 (DN26324_c1_g1_i3) and serine/threonineprotein kinase fray2 (DN28256_c1_g2_i10) which are involved in regulation of cell division. The gene MEI2-like 2 is believed to be involved in meiotic cell cycle and positive regulation of meiotic nuclear division whereas, gene serine/threonine-protein kinase is involved in regulation of mitotic cell cycle, signal transduction by protein phosphorylation and in stress-activated protein kinase signalling cascade [41]. Up-regulation of such genes denotes the active response of plant cells towards alkalinity stress.

\section{Alkalinity responsive and tolerance genes}

In order to study the molecular mechanism of alkalinity tolerance, alkalinity responsive and tolerance genes were identified by studying their differential expression in sensitive $\mathrm{v} / \mathrm{s}$ tolerant cultivars under control and stress conditions. Common genes that were differentially regulated between the two cultivars under treated conditions but remained unchanged under control condition are herein mentioned as "responsive genes" while genes that were differentially regulated under stress condition in tolerant cultivar as compared to sensitive one are addressed as "tolerance genes". Putative alkali responsive genes observed in this study have previously been reported to modulate similar or other abiotic stress responses. For example, major latex protein (MLP)-like protein has been identified as positive regulator of drought stress in Arabidopsis via ABA dependent pathway [42]. Similarly, Monks et al. [43] demonstrated the role of $S s h 1 p$, a phosphatidylinositol transfer protein in synthesis of osmoprotectant phosphoinositide under hyper-osmotic stress. Also, Zhang et al. [34] reported enhanced activity of SOD along with accumulation of superoxide anions in roots of Oryza sativa during alkalinity stress.

Amino acid proline is amongst the most abundantly accumulated osmo-protectant in plants during stress period [44]. Similar results were found in the present investigation where, PDL-1 accumulated more proline and showed less salt injury as compared to L-4076. This is due to upregulation of $\Delta 1$-Pyrroline-5-carboxylate synthetase (P5CS), which is a rate-limiting enzyme involved in biosynthesis of proline [45]. Similar to our observation, Kishor et al. [46] observed that, over-expression of P5CS leads to osmotic tolerance induction in plants via enhanced proline production. Apart from previously reported genes, we also observed some novel alkali responsive genes such as Phytochromobilin:ferredoxin oxidoreductase, Cyclin-U1-1, MLP-like protein 423, etc. which are involved in chloroplast-nucleus signalling pathway, phytochromobilin biosynthetic process, cell division and positive regulation of ABA signal transduction, respectively. The genes involved in cell division regulation and ABA signalling are actively involved in stress tolerance mechanisms of plants [47].

In the present study, DEGs were categorized into 14 functional categories i.e. phyto-hormones, light reactions, transcription factors, stomatal regulation, mitosis, nodulation, root-shoot growth \& development, epigenetics, chlorophyll synthesis, ion transporters, endo-membrane trafficking, calcium and lipid metabolism. Li et al. [19] also reported up-regulation of similar DEGs viz. light reactions, ion transport and root meristem growth in two contrasting rice genotypes under alkali stress. In another study, transcription factors like bHLH, bZIP, $\mathrm{NAC}$, etc. were found to be activated along with calcium signalling induced accumulation of $\mathrm{H}_{2} \mathrm{O}_{2}$ and secondary metabolites in wild jujube, which is in line with this study [18].

\section{Alkali responsive pathways activated during stress treatment}

In the present study, most of the DEGs belonged to biological and cellular processes especially to phytohormones and secondary metabolism involved in detoxification of alkali salts. Similar cascade of cellular response under $\mathrm{NaHCO}_{3}$ stress was also noticed in soybean, where alkaline modulated genes were found to be involved in metabolism, energy, signal transduction, and transcription [48]. Present findings are also in line with other studies under salinity stress $[49,50]$. MapMan analyses revealed pathways which were actively involved in alkalinity response viz. secondary metabolism pathways involved in biosynthesis of flavonoids \& lignin; shikimate and MVA pathways together with pathways involved in synthesis of antioxidants like phenolic acids, anthocyanins, etc. Similar to our study, Zhang et al. [17] also reported involvement of secondary metabolism pathways viz. phenylpropanoid and phenyl alanine metabolism in tolerance towards alkalinity stress in soybean.

Secondary metabolites such as phenolics and flavonoids are antioxidants that are involved in neutralization of ROS generated during stress [51]. These are actively recruited in tolerance mechanisms against oxidative stress [52]. Therefore, upregulation of such DEGs is well justified. Apart from secondary metabolism, phyto-hormone biosynthesis pathways, anti-oxidative enzymes, 
biotic and abiotic stress signalling pathways got activated during alkali treatment in both the cultivars. Similarly, other studies also found secondary metabolism, calcium signalling and phyto-hormone synthesis pathways activated during alkalinity stress conditions [18-20].

Transcription factors also play a major role in gene expression under varied environmental conditions. Major transcription factors found in response to alkalinity stress belonged to NAC (Trinity ID- DN22008 c0_g1_i2), bZIP (Trinity ID-DN14140_c0_g1_i3), and ZF (Trinity ID-DN32866_c1_g1_i6) families. Most of these transcription factors are involved in biosynthesis of chlorophyll and have regulatory function during stress response. Similar transcription factors (NAC and bZIP) were also found by Li et al. [19] in transcriptome analysis of two contrasting rice genotypes under alkali stress. Transcription factors involved in regulation of phytohormones i.e. ABA, jasmonates, cytokinins, indole acetic acid, etc. were also stimulated in both the cultivars under alkali stress.

During alkali stress, root cells are mostly prone to cell wall damage, which is mostly attributed to ROS generation [36]. Therefore, cultivar L-4076 showed maximum root cell damage compared to PDL-1. Activation of cell wall biosynthesis and modification mechanism is representative of cellular response against alkali stress. Evidently, major up-regulated DEGs such as Transcriptional corepressor LEUNIG_HOMOLOG (DN28191_c0_g1_i 13), Outer membrane protein Omp38 (DN12719_c0_g1_ i1), Probable galacturonosyl transferase 11 (DN32815 c0_g1_i1) identified in the present study belonged to cell wall modification functional group.

\section{$A B A$ signalling pathway: the most responsive pathway under alkalinity stress}

ABA signalling was found to be the most prominent pathway activated in both the cultivars during alkalinity stress. Plant cells respond to various abiotic stresses in two ways; either through ABA dependent or independent pathways [53]. ABA dependent pathway is reported to be the most common pathway responsible for providing tolerance against various abiotic stresses like drought, cold, salinity etc. [54]. DEGs up-regulated between sensitive and tolerant cultivars were responsible for ABA stress signalling. Related DEGs which were significantly up-regulated in the present study includes dehydrin 1 (DHN1) (DN27872_c0_g1_i2), 9-cis-epoxycarotenoid dioxygenase 1 (NCED1) (DN29751_c0_g1_i1), ABA-responsive protein 18 (ABR18) (DN28897_c0_g1_i1) and BEL1-like homeodomain protein 1 (BLH1) (DN14830_c0_g1_i3).

DHN1 is a stress responsive protein involved in response to $\mathrm{ABA}$ and water scarcity [55]. Dehydrins play important role in sustaining integrity of membrane enzymes and nucleotides [56]. Dehydrin gene was also found to be up-regulated in response to drought and cold stress in transcriptome analyses of barley [57]. Similarly, Kumar et al. [58] overexpressed OsDhn1 gene and improved drought and salinity tolerance in rice. Other genes like NCED1, ABR18 and BEL1-like homeodomain protein 1 are also involved in regulation of stress response through ABA signalling [59]. NCED catalyzes an oxidative cleavage reaction, which is the regulatory step in ABA synthesis from carotenoids [60]. On the other hand, BLH1 has role in ABA mediated seed dormancy and early seedling development [61]. In this study Kim et al. [61] found that Arabidopsis BLH1 over-expressing lines were hypersensitive to ABA and salinity, and exhibited increased expression of ABA-responsive genes, such as ABI3 and ABI5. Up-regulation of ABA responsive DEGs in the present investigation clearly indicates the role of $\mathrm{ABA}$ hormone in response to the alkalinity stress in both the cultivars. On the contrary, ABR18-like genes were found to be downregulated in tolerant chickpea cultivars as compared to the sensitive ones under salt stress [62].

\section{Identification of molecular markers}

SSRs and SNPs are considered to be invaluable markers for crop breeding. Under control conditions, both the cultivars showed maximum variants compared to the treated conditions. The data generated in this study will be helpful in developing an understanding of molecular response of plants under alkalinity stress which can be utilized in future breeding programs of lentil and related species.

\section{qRT-PCR validation}

Ten DEGs selected for qRT-PCR validation were involved in ABA signal transduction; hormones and ion transport; proline accumulation and other regulatory genes. For $1 \mathrm{C}-1 \mathrm{~T}$, three genes were used: proline dehydrogenase 2 , MLP-like protein 423, and cyclin-dependent kinase G-2 (CDKG-2). Proline dehydrogenase is responsible for oxidation of proline and synthesis of glutamate. Its suppression causes proline accumulation during abiotic stresses and thus enhances resistance towards these stresses [63]. MLP-like protein 23 gene is involved in ABA response regulation in Arabidopsis [40]. CDKG-2 is involved in cell cycle and gene expression regulation and has an important role in regulation of cellular processes during abiotic stresses [64].

For $2 \mathrm{C}-2 \mathrm{~T}$, three genes namely, inactive poly [ADPribose] polymerase RCD1, xyloglucan endotransglucosylase and ferritin-2 were employed. Inactive poly [ADP-ribose] polymerase RCD1 gene is involved in regulation of oxidative stress, hormonal and developmental response, etc. [64]. Gene xyloglucan 
endotransglucosylase is involved in abiotic stress response and participate in many physiological roles such as cell wall modifications during stress [65]. The gene was found to be responsible for improved drought and salt tolerance in transgenic Arabidopsis [66]. Ferritin gene is involved in abiotic stress response in plants and in ROS scavenging activities. In a study on wheat, over expression of ferritin gene conferred improved tolerance to heat and other abiotic stresses [67].

For $1 \mathrm{~T}-2 \mathrm{~T}$, four genes namely, auxin transport protein BIG, $\mathrm{ABC}$ transporter $\mathrm{G}$ family member 25 , protein ZINC INDUCED FACILITATOR-LIKE 1 and probable serine/threonine-protein kinase SIS8 were used for validation of identified DEGs. Most of the genes used were involved in abiotic stress response, transport of ion and, hormones, etc.

BIG is required for auxin efflux and polar auxin transport which affects auxin mediated developmental responses like cell elongation, lateral root development, apical dominance etc. [68]. ABC transporter G family member 25 arbitrates $A B A$ export through plasma membrane, especially in vascular tissues and brings in intercellular ABA signalling [69]. ZINC INDUCED FACILITATOR-LIKE 1 is associated with auxin efflux and functions as a positive regulator of upward transport towards shoot at the root apex. It also imparts proton efflux from the vacuolar compartment [70]. Probable serine/threonine-protein kinase SIS8 has been reported to act as a negative regulator of salt tolerance in Arabidopsis [71]. Conclusively, the qRT-PCR expression patterns validated differential expression of genes obtained from Illumina sequencing.

\section{Conclusions}

Present investigation reports the transcriptome analysis of lentil seedlings and its putative molecular mechanism in response to alkalinity stress. The study revealed that active pathways for alkalinity stress tolerance in lentil are phyto-hormones biosynthesis-predominantly through ABA signalling and secondary metabolism, which are also known to be actively involved in other abiotic stress response mechanisms. PDL-1 showed pronounced tolerance towards alkali stress compared to L-4076 owing to low accumulation of $\mathrm{Na}^{+}$and high accumulation of $\mathrm{K}^{+}$ in both roots and shoots. The cultivar also maintained high cellular integrity and physiol-cytological status under stress condition based on mitotic index, antioxidant production, osmolytes accumulation and membrane stability. Since, the cultivar was previously found to be resistant to drought and salinity also; it can be utilized as novel genetic resource for climate smart lentil breeding. SSRs and SNPs identified under alkali stress response can be developed as genomic resources for mapping and tagging of genes for breeding alkali tolerance traits in lentils and related species.

\section{Material and method}

Plant material, growth and alkalinity treatment

Two cultivars namely, PDL-1 (alkalinity tolerant) and L-4076 (alkalinity sensitive) were assayed to study the effects of alkalinity stress on plants. These two cultivars were developed at Indian Council of Agricultural Research (ICAR)-Indian Agricultural Research Institute (IARI), New Delhi, India. The experiments were conducted under hydroponic condition provided at National Phytotron Facility (NPF), ICAR-IARI, New Delhi, India. Sterilized seeds of both the cultivars were germinated under control condition, programmed at a temperature of $20-24{ }^{\circ} \mathrm{C}$ for $16 \mathrm{~h}$ light $/ 8 \mathrm{~h}$ dark photoperiod.

\section{Characterization of morpho-anatomical and cytological changes}

Seven days old seedlings were transferred to hydroponics, wherein they were subjected to alkalinity stress $(40 \mathrm{mM}$ $\mathrm{NaHCO}_{3} ; \mathrm{pH}$ 9.1) conditions for next 3, 5 and 7 days. No trace of $\mathrm{NaHCO}_{3}$ was added to control. The chemical composition of the nutrient solution and treatment conditions were applied following the methods described by Ge et al. [48] with partial modifications. Plants of tolerant cultivar (PDL-1) under control condition were named $1 \mathrm{C}$ followed by sensitive cultivar (L-4076) under control condition as $2 \mathrm{C}$. Similarly, tolerant and sensitive cultivars when exposed to $40 \mathrm{mM} \mathrm{NaHCO}_{3}$ stress were named as $1 \mathrm{~T}$ and $2 \mathrm{~T}$, respectively. To examine the effects of alkalinity stress on morphological traits at different time lengths, the most prominent symptoms i.e. wilting and necrosis were evaluated.

Anatomical changes within the contrasting cultivars were checked by free hand cross sectioning of roots and shoots using razor blades. Toluidine blue (50\%) staining method was applied for categorization of tissues on the basis of different colours. These cross-sections were visualised as well as photographed under optical microscope (Zeiss AXIOSKOP 2, Germany).

Effects of alkalinity stress on roots were studied by calculating MI in root tips after $4 \mathrm{~h}, 6 \mathrm{~h}, 24 \mathrm{~h}$ and $48 \mathrm{~h}$ of treatment. Root tips from five seedlings were taken and stained as described by Zhang et al. [72]. MI was calculated by dividing average number of dividing cells with average number of cells in the five microscopic field views under observation at a particular time.

\section{Evaluation of physio-biochemical parameters}

To differentiate physio-biochemical activities within the leaves of tolerant and sensitive cultivars under 
control and alkalinity stress conditions, parameters such as RWC, MSI and photosynthetic pigments (total chlorophyll) were measured. Antioxidants enzymes such as SOD, APX, GPX and catalase were also deduced. Accumulation of different osmolytes such as glycine betaine, proline and soluble sugars were estimated for both the cultivars. All the above-mentioned parameters were deduced following the methods described by Singh et al. $[15,22,73]$. ABA was also estimated from the roots of both the cultivars under control and stress conditions following the protocol described by Zeevaart [74]. $\mathrm{Na}^{+}$and $\mathrm{K}^{+}$contents in the roots and leaves were elucidated under control and alkalinity stress conditions using Flame Photometer (Systronics, India) as described by Singh et al. [4]. $\mathrm{H}_{2} \mathrm{O}_{2}$ levels in root tips were detected using FDA staining method following Singh et al. [4].

\section{RNA isolation and Complementary Deoxy-ribonucleic acid (cDNA) library preparation}

The transcriptomic experiment was conducted using three biological replicates, consisting of 12 seedlings each from the contrasting cultivars (PDL-1 and L-4076) under control and alkalinity stress conditions. Total RNA was isolated from seedling leaf tissue, using QIAGEN RNeasy Plant Mini kit (QIAGEN, Hilden, Germany). Isolated RNA was purified and checked for integrity using Bioanalyzer (Agilent 2100, USA) to follow Illumina library construction and qRT-PCR. From the total extracted RNA, poly(A) messenger RNA (mRNA) was isolated using oligo(dT) beadsbased affinity chromatography. Library was prepared using TruSeq $^{\text {TM }}$ RNA Sample Prep kit (Illumina Inc., USA). Isolated and enriched mRNA was further fragmented using magnetic beads containing poly(T) molecules, which was then reverse transcribed into cDNA using random primers. The quality and quantity of cDNA was assessed using Agilent 2100 bioanalyzer and cDNA was purified using AMPure XP beads (Beckman Coulter, USA). Adapters were ligated to the ends of repaired cDNA fragments. Clusters were generated by selective amplification of fragments which have adapters ligated at both the ends. Sequencing was performed on Illumina HiSeq 2000 platform (Illumina, Inc. USA) to generate $2 \times 100$ bp paired end reads.

\section{Sequencing, data filtering and assembly}

Raw data obtained from sequencing was converted into nucleotide sequence by base-calling and selective filtration to remove reads below $30 \mathrm{bp}$ and having Phred quality score $(\mathrm{Q})$ less than 20. Prior to de novo transcriptome assembly, raw Fastq files were trimmed by removing the first two bases, last ten bases and adapter sequences from all the reads. Quality filtered reads thus generated were taken further for de novo transcriptome assembly using de novo Assembler (Trinity V 2.8.6) [75]. De novo contigs were obtained by assembling clean paired end reads. Trimmed reads were aligned to the assembled transcriptome using Bowtie program (V 1.2.3) [76].

\section{Differential gene expression and functional annotation}

DEGs were identified using EdgeR software with set parameters including read counts $\geq 1, p$ adjusted $\leq 0.05$, false discovery rate $(\mathrm{FDR})<0.01$ and absolute $\log _{2}$ fold change $\geq 1$. The transcripts that were differentially expressed were annotated by basic local alignment search tool (BLAST) of National Centre for Biotechnology Information (NCBI) with non-redundant (nr) protein database. Only the matches with E-value $\leq 10^{-5}$ as well as similarity score $\geq 40 \%$ were further used for functional annotation. Gene Ontology (GO) terms of transcripts were extracted for annotated DEGs and then segregated into different functional categories using Web Gene Ontology Annotation (WEGO V 2.0) [77]. Mapman (v3.51R2) analysis was performed to associate molecular pathways with annotated DEGs [78].

\section{SNP and SSR calling}

To further utilize the application of transcriptomic data, SNP and SSR variants were called from the assembled RNA-Seq data. SAMtools mpileup (V2.1) [79] and custom script were used for SNP variant calling based on the minimum read depth of 10. Genome Analysis Tool Kit (GATK) [80] software was used for calling SNPs using haplotype caller (command version 3.6-0) with all the default parameters. For SSR calling, high quality filtered reads that aligned with the contigs were deduced using MIcro SAtellite identification (MISA, V1.1) software [81].

\section{qRT-PCR validation}

For qRT-PCR validation, 10 significant genes were organized in three different combinations for comparison of expression between $1 \mathrm{C}$ and $1 \mathrm{~T} ; 1 \mathrm{~T}$ and $2 \mathrm{~T} ; 2 \mathrm{C}$ and $2 \mathrm{~T}$. Total RNA was isolated from the leaves of control and alkalinity-treated cultivars (PDL-1 and L-4076). RNA was quantified using NanoDrop ${ }^{\text {тм }}$ Spectrophotometer (Thermo Fisher Scientific, USA) and reverse transcribed to cDNA using Biorad cDNA synthesis kit (Biorad, USA). The expression of genes was normalized using $\beta$-tubulin as the reference gene. Primers were designed using Primer3Plus software. The qRT-PCR reaction was carried out in $25 \mu \mathrm{L}$ PCR reaction mixture consisting of $4 \mu \mathrm{g}$ diluted CDNA, $4 \mu \mathrm{L}$ each of forward and reverse primers and 12 $\mu \mathrm{L}$ SYBR Green dye in qRT-PCR cycler (Bio-Rad, USA) programmed at the following PCR cycle: $50{ }^{\circ} \mathrm{C}$ for $2 \mathrm{~min}$, $95^{\circ} \mathrm{C}$ for $10 \mathrm{~min}$ and 40 cycles consisting of $95^{\circ} \mathrm{C}$ for $15 \mathrm{~s}$ and $60{ }^{\circ} \mathrm{C}$ for $1 \mathrm{~min}$. Relative quantification of target genes expression was calculated using $2^{-\Delta \Delta C t}$ method [82]. 


\section{Supplementary Information}

The online version contains supplementary material available at https://doi. org/10.1186/s12870-022-03489-w.

Additional file 1: Fig.S1. Circos representing distribution of differentially expressed genes (DEGs) in lentil cultivars between combinations a) 1T-1C b) $2 \mathrm{~T}-2 \mathrm{C}$ and $1 \mathrm{~T}-2 \mathrm{~T}$, where 1C: PDL-1 control, 1T: PDL-1 treated, 2C: L-4076 control and 2T: L-4602 treated.

Additional file 2: Fig. S2. Relative expression of differentially expressed genes (DEGs) related to different cytological processes under alkalinity stress in lentil cultivars represented through BINs and Sub-BINs using MapMan Software.

Additional file 3: Fig. S3. Regression graph between expression data of next generation sequencing (NGS) and quantitative real time-polymerase chain reaction (qRT-PCR) of lentil cultivars under alkalinity stress.

Additional file 4: Table S1. Changes in mitotic index (MI) of lentil cultivars under normal and alkalinity treated conditions.

Additional file 5: Table S2. Details of contigs generated through de novo assembly in lentil samples under alkalinity stress.

Additional file 6: Table $\mathbf{S 3}$. Alkalinity responsive genes with $\log _{2}$ fold changes above 3 under alkalinity stress conditions in two contrasting lentil cultivars.

Additional file 7: Table S4. Categorical representation of different differentially expressed genes (DEGs) involved in alkalinity stress response in lentil cultivars.

Additional file 8: Table S5. List of 10 primers from combinations 1C-1T, $2 \mathrm{C}-2 \mathrm{~T}$ and $1 \mathrm{~T}-2 \mathrm{~T}$ used for validation of next-generation sequencing (NGS) data generated from lentil cultivars under alkalinity stress, where 1C: PDL-1 control, 1T: PDL-1 treated, 2C: L-4076 control and 2T: L-4602 treated.

\section{Acknowledgements}

Authors thank Director, Joint Director (Research), ICAR-Indian Agricultural Research Institute (IARI), New Delhi; Head, Division of Genetics and Incharge, National Phytotron Facility, IARI, New Delhi, for their support provided to accomplish the research activities. Authors also thank Mr. Ashwani Kumar Mishra, DNA Xperts Pvt Ltd, Delhi for support in Bioinformatics data analysis.

\section{Authors' contributions}

Conceived and designed the experiments: DS, MP, PCS and RKY. Performed the experiments: DS, CKS. Analyzed the data: DS, CKS, SKS, VS, SK and DPS. Contributed reagents/materials/ analysis tools: MP, PCS KG and RKY. Wrote the paper: DS, JT and CKS. All authors read and approved the final manuscript.

\section{Funding}

This work has been financially supported by Indian Council for Agricultural Research (ICAR)-Indian Agricultural Research Institute (IARI), New Delhi (Project no- JAN 09 / 16). The funding bodies had no role in the design of the study, data analysis, interpretation and writing the manuscript.

\section{Availability of data and materials}

All the data generated or analyzed during this study are included in this manuscript and its supporting information files. Sequences were deposited in Sequence Read Archive (SRA) (BioProject Accession: PRJNA685293).

\section{Declarations}

Ethics approval and consent to participate

Not applicable.

\section{Consent for publication}

Not applicable.

\section{Competing interest}

The authors declare that they have no conflict of interest.

\section{Author details}

${ }^{1}$ Division of Genetics, ICAR-Indian Agricultural Research Institute, New Delhi 110012, India. ${ }^{2}$ Division of Plant Physiology, Indian Agricultural Research Institute, New Delhi 110012, India. ${ }^{3}$ ICAR-National Institute of Plant Biotechnology, 110012 New Delhi, India. ${ }^{4}$ Division of Crop Improvement, Central Soil Salinity Research Institute, 132001 Karnal, India. ${ }^{5}$ Depatment of Botany, Meerut College, 250001 Meerut, India. ${ }^{6}$ Department of Genetics and Plant Breeding, Chandra Shekhar Azad University of Agriculture and Technology, 208002 Kanpur, India.

Received: 28 July 2021 Accepted: 3 December 2021

Published online: 05 March 2022

\section{References}

1. Shi D, Wang D. Effects of various salt-alkaline mixed stresses on Aneurolepidium chinense Trin Kitag. Plant Soil. 2005; 271: 15-26. https://doi.org/10. 1007/s11104-004-1307-z

2. López-Bucio J, Guevara-García A, Ramírez-Rodríguez V, Nieto MF, HerreraEstrella L. Agriculture for marginal lands: transgenic plants towards the third millennium. In Plant genetic engineering: towards the third millennium: Proceedings of the International Symposium on Plant Genetic Engineering, Havana, Cuba. 2000;6-10(1999):159-65.

3. Wang X, Geng S, Ma Y, Shi D, Yang C, Wang H. Growth, photosynthesis, solute accumulation, and ion balance of tomato plant under sodium- or potassium-salt stress and alkali stress. Agronomy J. 2015;107:651.

4. Singh D, Singh CK, Singh YP, Singh, V, Singh, R, Tomar RSS, Sanwal SK, Karwa S, Mishra VK, Sarkar SK,Pal M. Evaluation of cultivated and wild genotypes of Lens species under alkalinity stress and their molecular collocation using microsatellite markers. PloS One. 2018; 13: pe0199933

5. Tewari TN, Singh BB. Stress studies in lentil Lens esculenta Moench. Plant Soil. 1991; 136: 225-230. https://doi.org/10.1007/BF02150053

6. Guo R, Shi L, Yang Y. Germination, growth, osmotic adjustment and ionic balance of wheat in response to saline and alkaline stresses. Soil Sci Plant Nutr. 2009:55:667-79.

7. Zhang JT, Mu CS. Effects of saline and alkaline stresses on the germination, growth, photosynthesis, ionic balance and anti-oxidant system in an alkali-tolerant leguminous forage Lathyrus quinquenerviu. Soil Sci Plant Nutr. 2009;55:685-97.

8. Zhao Q, Suo J, Chen S, Jin Y, Ma X, Yin Z, Zhang Y, Wang T, Luo J, Jin W, Zhang X. $\mathrm{Na}_{2} \mathrm{CO}_{3}$-responsive mechanisms in halophyte Puccinellia tenuiflora roots revealed by physiological and proteomic analyses. Sci Rep. 2016;6(1):1-23.

9. Takahashi M, Nakanishi H, Kawasaki S, Nishizawa NK, Mori S. Enhanced tolerance of rice to low iron availability in alkaline soils using barley nicotianamine aminotransferase genes. Nat Biotechnol. 2001;19:466-9.

10. Ogo Y, Itai RN, Kobayashi T, Aung MS, Nakanishi H, Nishizawa NK. OsIRO is responsible for iron utilization in rice and improves growth and yield in calcareous soil. Plant Mol Biol. 2011;75:593-605.

11. Yang Y, Qin Y, Xie C, Zhao F, Zhao J, Liu D, Chen S, Fuglsang AT, Palmgren MG, Schumaker KS, Deng XW. The Arabidopsis chaperone J3 regulates the plasma membrane $\mathrm{H}^{+}$-ATPase through interaction with the PKS5 kinase. Plant Cell. 2010;22:1313-32.

12. Guo M, Wang R, Wang J, Hua K, Wang Y, Liu X, Yao S. ALT1, a Snf2 family chromatin remodeling ATPase, negatively regulates alkaline tolerance through enhanced defense against oxidative stress in rice. PLoS One. 2014; 9: pe112515

13. Joshi M, Timilsena Y, Adhikari B. Global production, processing and utilization of lentil: A review. J Integr Agric. 2017;16:2898-913. https://doi. org/101016/s2095-31191761793-3.

14. Singh D, Singh CK, Kumari S, Tomar RSS, Karwa S, Singh R, Singh RB, Sarkar SK, Pal M. Discerning morpho-anatomical, physiological and molecular multiformity in cultivated and wild genotypes of lentil with reconciliation to salinity stress. PloS One. 2017; 12:pe0177465

15. Singh D, Singh CK, Tomar RSS, Chaturvedi AK, Shah D, Kumar A, Pal M. Exploring genetic diversity for heat tolerance among lentil Lens culinaris Medik genotypes of variant habitats by simple sequence repeat markers. Plant Breed. 2016 a: 135: 215-223

16. Zhang C, Bian M, Yu H, Liu Q, Yang Z. Identification of alkaline stressresponsive genes of CBL family in sweet sorghum Sorghum bicolor $\mathrm{L}$. 
Plant Physiol Biochem. 2011;49:1306-12. https://doi.org/10.1016/jplap hy201108010.

17. Zhang J, Wang J, Jiang W, Liu J, Yang S, Gai J, Li Y. Identification and Analysis of NaHCO 3 stress responsive genes in wild Soybean Glycine soja roots by RNA-seq. Front Plant Sci. 2016;7:1842. https://doi.org/10.3389/ fpls201601842.

18. Guo M, Li S, Tian S, Wang B, Zhao X. Transcriptome analysis of genes involved in defense against alkaline stress in roots of wild jujube Ziziphus acidojujuba. PloS One. 2017;12:e0185732. https://doi.org/10.1371/journ alpone0185732.

19. Li N, Liu H, Sun J, Zheng H, Wang J, Yang L, Zhao H, Zou D. Transcriptome analysis of two contrasting rice cultivars during alkaline stress. Sci Rep. 2018;8:1-16. https://doi.org/10.1038/s41598-018-27940-x.

20. Meng C, Quan TY, Li ZY, Cui KL, Yan L, Liang Y, Dai JL, Xia GM, Liu SW. Transcriptome Profiling reveals the genetic basis of alkalinity tolerance in wheat. BMC Genomics. 2017;18:1-14. https://doi.org/10.1186/ s12864-016-3421-8

21. Zou C, Liu D, Wu P, Wang Y, Gai Z, Liu L, Yang F, Li C, Guo G. Transcriptome analysis of sugar beet (Beta vulgaris $\mathrm{L}$.) in response to alkaline stress. Plant Mol Biol. 2020; 102(6):645-57.

22. Singh D, Singh CK, Tomar RSS, Taunk J, Singh R, Maurya S, Chaturvedi AK, Pal M, Singh R, Dubey SK. Molecular assortment of Lens species with different adaptations to drought conditions using SSR markers. PLoS One. 2016;11:pe0147213.

23. Singh D, Singh CK, Taunk J, Jadon V, Pal M, Gaikwad K. Genome wide transcriptome analysis reveals vital role of heat responsive genes in regulatory mechanisms of lentil (Lens culinaris Medikus). Sci. Rep. 2019;10:9(1):1-9.

24. Wang Y, Ma H, Liu G, Zhang D, Ban Q, Zhang G, Xu C, Yang C. Generation and analysis of expressed sequence tags from a $\mathrm{NaHCO}_{3}$-treated Limonium bicolor cDNA library. Plant Physiol Biochem. 2008;46:977-86.

25. Rao PS, Mishra B, Gupta SR. Effects of Soil Salinity and Alkalinity on Grain Quality of Tolerant, Semi-Tolerant and Sensitive Rice Genotypes. Rice Sci. 2013;20:284-91. https://doi.org/10.1016/S1672-6308(13)60136-5.

26. Singh D, Singh CK, Taunk J, Tomar RSS, Chaturvedi AK, Gaikwad K, Pal $M$. Transcriptome analysis of lentil Lens culinaris Medikus in response to seedling drought stress. BMC Genomics. 2017;18:206.

27. Saberali SF, Moradi M. Effect of salinity on germination and seedling growth of Trigonellafoenum-graecum, Dracocephalum moldavica, Satureja hortensis and Anethum graveolens. J. Saudi Soc Agric Sci. 2019;18:316-23. https://doi.org/10.1016/jjssas201709004.

28. Lai L, Chen L, Zheng M, Jiang L, Zhou J, Zheng Y, Shimizu H. Seed germination and seedling growth of five desert plants and their relevance to vegetation restoration. Ecol Evol. 2019;9:2160-70. https://doi.org/10. 1002/ece34910

29. Rajabi DA, Zahedi M, Ludwiczak A, Cardenas PS, Piernik A. Effect of salinity on seed germination and seedling development of sorghum Sorghum bicolor L Moench genotypes. Agronomy. 2020;10:859.

30. Shannon MC, Grieve CM. Tolerance of vegetable crops to salinity. SC Hortic. 1998;78:5-38.

31. Brini F, Masmoudi K. Ion Transporters and Abiotic Stress Tolerance in Plants. Int. Sch. Res. Notices. 2012. https://doi.org/10.5402/2012/927436

32. Falhof J, Pedersen JT, Fuglsang AT, Palmgren M. Plasma Membrane $\mathrm{H}+$-ATPase Regulation in the Center of Plant Physiology. Mol Plant 2016;2016(9):323-37. https://doi.org/10.1016/jmolp201511002.

33. Biswas MS, Mano J. Lipid peroxide-derived short-chain carbonyls mediate hydrogen peroxide-induced and salt-induced programmed cell death in plants. Plant Physiol. 2015;168:885-98. https://doi.org/10.1104/pp115 256834.

34. Zhang H, Liu XL, Zhang RX, Yuan HY, Wang MM, Yang HY, Ma HY, Liu D, Jiang CJ, Liang ZW. Root damage under alkaline stress is associated with reactive oxygen species accumulation in rice Oryza sativa L. Front Plant Sci. 2017:8:1580.

35. Bernards MA, Summerhurst DK, Razem FA. Oxidases, peroxidases and hydrogen peroxide: The suberin connection. Phytochem. Rev. 2004; 3: 113-126 https://doi.org/10.1023/B:PHYT00000478101070646

36. Zhang X, Yao Y, Li X, Zhang L, Fan S. Transcriptomic analysis identifies novel genes and pathways for salt stress responses inSuaeda salsaleaves. Sci Rep. 2020;10:1-12. https://doi.org/10.1038/s41598-020-61204-x.

37. Xiaoyan C, Qin S, He B. Effect of salt stress on mitosis of root tip cell in rye Secale cereal. Acta Agric Bor Sin. 2004;13(2):24-7.
38. Singh D, Roy BK. Salt stress affects mitotic activity and modulates antioxidant systems in onion roots. Braz J Bot. 2016;39:67-76.

39. Radic S, Prolic M, Pavlica M, Pevalekkozlina B. Cytogenetic effects of osmotic stress on the root meristem cells of Centaurea ragusina L. Environ Exp Bot. 2005;54:213-8.

40. Cooke MS, Evans MD, Dizdaroglu M, Lunec J. Oxidative DNA damage: mechanisms, mutation, and disease. FASEB J. 2003:17:1195-214.

41. Kaur J, Sebastian J, Siddiqi I. The Arabidopsis-mei2-like genes play a role in meiosis and vegetative growth in Arabidopsis. Plant Cell. 2006;18(3):545-59.

42. Wang Y, Yang L, Chen X, Ye T, Zhong B, Liu R, Wu Y, Chan Z. Major latex protein-like protein 43 MLP43 functions as a positive regulator during abscisic acid responses and confers drought tolerance in Arabidopsis thaliana. J Exp Bot. 2016;67:421-34. https://doi.org/10.1093/jxb/erv477.

43. Monks DE, Aghoram K, Courtney PD, DeWald DB, Dewey RE. Hyperosmotic stress induces the rapid phosphorylation of a soybean phosphatidylinositol transfer protein homolog through activation of the protein kinases SPK1 and SPK2. Plant Cell. 2001;13:1205-19.

44. Majumder AL, Sengupta S, Goswami L. Osmolyte regulation in abiotic stress In Abiotic stress adaptation in plants Springer, Dordrecht. 2009. p. 349-70.

45. Hong Z, Lakkineni K, Zhang Z, Verma DP. Removal of feedback inhibition of delta1-pyrroline-5-carboxylate synthetase results in increased proline accumulation and protection of plants from osmotic stress. Plant Physiol. 2000;122:1129-36. https://doi.org/10.1104/pp12241129.

46. Kishor PK, Hong Z, Miao GH, Hu CA, Verma DP. Overexpression of [delta]pyrroline-5-carboxylate synthetase increases proline production and confers osmotolerance in transgenic plants. Plant Physiol. 1995;108:1387-94.

47. Sah SK, Reddy KR, Li J. Abscisic acid and abiotic stress tolerance in crop plants. Front PlantSci. 2016;7:571. https://doi.org/103389/fpls201600571.

48. Ge Y, Li Y, Zhu YM, Bai X, Lv DK, Guo D, Ji W, Cai H. Global transcriptome profiling of wild soybean (Glycine soja) roots under $\mathrm{NaHCO}_{3}$ treatment. BMC Plant Biol. 2010;10(1):1-4.

49. Kaashyap M, Ford R, Kudapa H, Jain M, Edwards D, Varshney R, Mantri N. Differential regulation of genes involved in root morphogenesis and cell wall modification is associated with salinity tolerance in Chickpea. Sci Rep. 2018;8:1-9. https://doi.org/10.1038/s41598-018-23116-9.

50. Xiong $Y$, Yan H, Liang $H$, Zhang Y, Guo B, Niu M, Jian S, Ren H, Zhang X, L Y, Zeng S, Wu K, Zheng F, Teixeira da Silva JA, Ma G. RNA-Seq analysis of Clerodendrum inerme $\mathrm{L}$ roots in response to salt stress. BMC Genomics. 2019;20:1-18. https://doi.org/10.1186/s12864-019-6098-y.

51. Hasanuzzaman M, Bhuyan M, Zulfigar F, Raza A, Mohsin SM, Mahmud JA, Fujita M, Fotopoulos V. Reactive oxygen species and antioxidant defense in plants under abiotic stress: Revisiting the crucial role of a universal defense regulator. Antioxidants. 2020;9:681. https://doi.org/10.3390/antio x9080681.

52. Isah T. Stress and defense responses in plant secondary metabolites production. Biol Res. 2019;52:39. https://doi.org/10.1186/s40659-019-0246-3.

53. Tuteja N. Abscisic acid and abiotic stress signalling. Plant Signal Behav. 2007; 2: 135-138 https://doi.org/10.4161/psb234156

54. Matsui A, Ishida J, Morosawa T, Mochizuki Y, Kaminuma E, Endo TA, Okamoto M, Nambara E, Nakajima M, Kawashima M, Satou M. Arabidopsis transcriptome analysis under drought, cold, high-salinity and ABA treatment conditions using a tiling array. Plant Cell Physiol. 2008;49:1135-49.

55. Hanin M, Brini F, Ebel C, Toda Y, Takeda S, Masmoudi K. Plant dehydrins and stress tolerance: versatile proteins for complex mechanisms. Plant Signal Behav. 2011;6:1503-9. https://doi.org/10.4161/psb61017088.

56. Yu Z, Wang X, Zhang L. Structural and functional dynamics of dehydrins: a plant protector protein under abiotic stress. Int J Mol Sci. 2018:19(11):3420.

57. Tommasini L, Svensson JT, Rodriguez EM, Wahid A, Malatrasi M, Kato K, Wanamaker S, Resni J, Close TJ. Dehydrin gene expression provides an indicator of low temperature and drought stress: transcriptome-based analysis of barley Hordeum vulgare L. Funct IntegrGenomics. 2008;8:387405. https://doi.org/10.1007/s10142-008-0081-z.

58. Kumar M, Lee SC, Kim JY, Kim SJ, Kim SR. Over-expression of dehydrin gene, OsDhn1, improves drought and salt stress tolerance through scavenging of reactive oxygen species in rice Oryza sativa L. J Plant Biol. 2014;57:383-93. https://doi.org/10.1007/s12374-014-0487-1.

59. Huang Y, Guo Y, Liu Y, Zhang F, Wang Z, Wang H, Wang F, Li D, Mao D, Luan S, Liang M, Chen L. 9-cis-Epoxycarotenoid Dioxygenase 3 regulates plant 
growth and enhances multi-abiotic stress tolerance in rice. Front Plant Sci. 2018;9:162. https://doi.org/103389/fpls201800162.

60. Cherny JT, Zeevaart JA. Characterization of the 9-cis-epoxycarotenoid dioxygenase gene family and the regulation of abscisic acid biosynthesis in avocado. Plant Physiol. 2000;124(1):343-54.

61. Kim D, Cho YH, Ryu H, Kim Y, Kim TH, Hwang I. BLH 1 and KNAT 3 modulate $A B A$ responses during germination and early seedling development in Arabidopsis. Plant J. 2013;75(5):755-66.

62. Kumar N, Soren KR, Bharadwaj C, PR SP, Shrivastava AK, Pal M, Roorkiwal M, Kumar K, Patil BS, Soni A, Nimmy MS. Genome-wide transcriptome analysis and physiological variation modulates gene regulatory networks acclimating salinity tolerance in chickpea. Environ Exp Bot. 2021; 187: 104478

63. Ibragimova SS, Kolodyazhnaya YS, Gerasimova SV, Kochetov AV. Partial suppression of gene encoding proline dehydrogenase enhances plant tolerance to various abiotic stresses. Russian J Plant Physiol. 2012;59:8896. https://doi.org/10.1134/S1021443712010086.

64. Kitsios G, Doonan JH. Cyclin dependent protein kinases and stress responses in plants. Plant Signal Behav. 2011;6:204-9. https://doi.org/10. 4161/psb6214835.

65. Teotia S, Lamb RS. The paralogous genes radical-induced cell death1 and similar to Rcd one1 have partially redundant functions during Arabidopsis development. Plant Physiol. 2009;151:180-98. https://doi.org/10.1104/ pp109142786.

66. Cho SK, Kim JE, Park JA, Eom TJ, Kim WT. Constitutive expression of abiotic stress-inducible hot pepper CaXTH3, which encodes a xyloglucan endotransglucosylase/hydrolase homolog improves drought and salt tolerance in transgenic Arabidopsis plants. FEBS Lett. 2006;580:3136-44 https://doi.org/10.1016/jfebslet200604062.

67. Zang $X$, Geng X, Wang F, Liu Z, Zhang L, Zhao Y, Tian X, Ni Z, Yao Y, Xin $M, H u Z$, Sun Q, Peng H. Overexpression of wheat ferritin gene TaFER-5B enhances tolerance to heat stress and other abiotic stresses associated with the ROS scavenging. BMC Plant Biol. 2017;17:14. https://doi.org/10, 1186/s12870-016-0958-2.

68. Gil P, Dewey E, Friml J, Zhao Y, Snowden KC, Putterill J, Palme K, Estelle M, Chory J. BIG: a calossin-like protein required for polar auxin transport in Arabidopsis. Genes Develop. 2001;15:1985-97.

69. Borghi L, Kang J, Ko D, Lee Y, Martinoia E. The role of ABCG-type $A B C$ transporters in phytohormone transport. Biochem Soc Transac. 2015;43(5):924-30.

70. Remy E, Cabrito TR, Baster P, Batista RA, Teixeira MC, Friml J, Sá-Correia I, Duque P. A major facilitator superfamily transporter plays a dual role in polar auxin transport and drought stress tolerance in Arabidopsis. Plant Cell. 2013;25(3):901-26.

71. Gao L, Xiang CB. The genetic locus At1 g73660 encodes a putative MAPKKK and negatively regulates salt tolerance in Arabidopsis. Plant Mol Biol. 2008:67(1):125-34.

72. Zhang H, Jiang Z, Qin R, Zhang H, Zou J, Jiang W, Liu D. Accumulation and cellular toxicity of aluminum in seedling of Pinus massoniana. BMC Plant Biol. 2014;14:1-6. https://doi.org/10.1186/s12870-014-0264-9.

73. Singh D, Pal M, Singh R, Singh CK, Chaturvedi AK. Physiological and biochemical characteristics of Vigna species for Al stress tolerance. Acta Physiol Plant. 2015:37:87.

74. Zeevaart JA. Changes in the levels of abscisic acid and its metabolites in excised leaf blades of Xanthium strumarium during and after water stress. Plant Physiol. 1980;66:672-8

75. Grabherr MG, Haas BJ, Yassour M, Levin JZ, Thompson DA, Amit I. Chen Z Full-length transcriptome assembly from RNA-Seq data without a reference genome. Nat Biotechnol. 2011;29:644. https://doi.org/10.1038/ nbt1883.

76. Langmead, Schatz MC, Lin J, Pop M, Salzberg SL Searching for SNPs with cloud computing. Genome Biol. 2009; 10:1-10. https://doi.org/10.1186/ gb-2009-10-11-r134

77. Ye J, Zhang Y, Cui H, Liu J, Wu Y, Cheng Y, Xu H, Huang X, Li S, Zhou A, Zhang X. WEGO 2.0: a web tool for analyzing and plotting $G O$ annotations. Nucleic Acids Res. 2018;2018(46):71-5.

78. Thimm O, Bläsing O, Gibon Y, Nagel A, Meyer S, Krüger P, Selbig J, Müller $L A$, Rhee SY, Stitt M. MAPMAN: a user-driven tool to display genomics data sets onto diagrams of metabolic pathways and other biological processes. Plant J. 2004;37:914-39.
79. Li H, Handsaker B, Wysoker A, Fennell T, Ruan J, Homer N, Marth G, Abecasis $\mathrm{G}$, Durbin R. The sequence alignment/map format and SAMtools. Bioinformatics. 2009;25:2078-9.

80. McKenna A, Hanna M, Banks E, Sivachenko A, Cibulskis K, Kernytsky A, Garimella K, Altshuler D, Gabriel S, Daly M, DePristo MA. The Genome Analysis Toolkit: a MapReduce framework for analyzing next-generation DNA sequencing data. Genome Res. 2010;20:1297-303.

81. Thiel T, Michalek W, Varshney R, Graner, A. Exploiting EST databases for the development and characterization of gene-derived SSR-markers in barley (Hordeum vulgare L.). Theor. Appl. Genet. 2003; 106: 411-422.

82. Livak KJ, Schmittgen TD. Analysis of relative gene expression data using real-time quantitative PCR and the $2^{-\triangle A C T}$ method. Methods. 2001; 25: 402-408

\section{Publisher's Note}

Springer Nature remains neutral with regard to jurisdictional claims in published maps and institutional affiliations. 